\title{
1. Introduction: Promoting green electricity in Europe: the challenge of integrating contextual factors
}

\author{
William M. Lafferty and Audun Ruud
}

Energy is what makes Europe tick. It is essential, then, for the European Union (EU) to address the major energy challenges facing us today, i.e. climate change, our increasing dependence on imports, the strain on energy resources and access for all users to affordable, secure energy. The EU is putting in place an ambitious energy policy - covering the full range of energy sources from fossil fuels (oil, gas and coal) to nuclear energy and renewables (solar, wind, biomass, geothermal, hydro-electric and tidal) - in a bid to spark a new industrial revolution that will deliver a low-energy economy, whilst making the energy we do consume more secure, competitive and sustainable.

(Activities of the European Union: Summaries of legislation, EC 2007)

\section{PROMOTING SUSTAINABLE DEVELOPMENT THROUGH GREEN ELECTRICITY}

The goal of pursuing sustainable development (SD) in Europe has been given top priority by the decision-making bodies of the European Union. At the highest level of political generalization, the task is viewed as a question of balance between the so-called Gothenburg and Lisbon agendas. While the former enunciates values, principles and policies designed to achieve a radically new form of development - a path where both economic and social aspirations are accommodated to environmental concerns - the latter aims to make Europe a more competitive, flexible and knowledge-based economy. The difference between the two paths was highlighted by the President of the European Commission, José Manuel Barroso, with an analogy to the family. Defending his particular emphasis at the time on the economic aspect of the Lisbon agenda, he stated: 'If one of my children is sick, I'm ready to drop everything and focus on that one, but that doesn't mean I love the others any less.' He went on to imply that the European economy was currently in poor health and needed more immediate attention before efforts could be 
made to strengthen the environmental and social agendas (European Environment 2005).

Regardless of how one feels about Barroso's family commitments, there can be little doubt that the competition between the two agendas, and among the three dimensions or 'pillars', has become a major line of contention within EU politics. While ostensibly embracing the pursuit of 'win-win' solutions and 'balance' among the competing sets of values and goals, major business, labour and environmental interests tend to line up on the one or the other side of the 'sustainability versus economic competitiveness' divide. This is in itself an interesting aspect of a general decline in 'right-left' politics within the EU. The three SD dimensions clearly reflect the market-liberalist, social-democratic and environmentalist values of earlier political movements. The ideological discourse has, however, gradually shifted to subsume the earlier lines of conflict within a broader discussion as to the nature and policy relevance of 'sustainable development'. Here the values of economic growth, on the one hand, and more consequent environmental protection on the other - with 'social sustainability' tending to share aspects of both - increasingly generate policy conflicts across the entire spectrum of sectoral interests. The political rhetoric of the Gothenburg-Lisbon divide has thus increasingly penetrated and 'coloured' the rhetoric of EU politics.

It is within this overarching political discourse on the nature and demands of 'sustainability' that the current study has been designed and carried out. Recognizing the enormous variation in approaches to sustainable development in Europe, the study focuses on a single crucial initiative for achieving SD goals: the promotion of 'renewable energy sources for electricity' (RES-E), commonly known as 'green electricity'. The choice of this particular SD initiative was made for several related reasons.

First, we were primarily interested in following up earlier studies of 'governance for sustainable development'. The common thread in all these studies is 'What works, where, when and how?', when governments attempt to realize SD goals and programmes. The focus of the research has progressed from relatively broad comparative analyses of SD implementation at the local-regional (Lafferty and Eckeberrg 1998; Lafferty 2001; Lafferty and Narodoslawsky 2003) and national (Lafferty and Meadowcroft 2000) levels, to more specialized and in-depth studies of specific cases and governing mechanisms (Lafferty and Meadowcroft 1996; Lafferty 2004; Lafferty et al. 2007). The present study continues this line of research by: (1) concentrating on a single initiative - the EU Directive 'on the promotion of electricity produced from renewable energy sources in the internal energy market' (OJEC 2001); and (2) investigating empirically how the 
initiative is being implemented in selected EU Member States (and one associated state, Norway).

Second, whereas we, in our earlier studies, have focused on broader SD strategies and action plans, the idea here is to narrow the scope of the 'common commitment' to a very specific task, with clear 'indicative targets'. We have thus narrowed the empirical focus to an initiative that has a higher degree of national (member-state) obligation than is the case with 'softer' commitments to SD within the United Nations system. We thereby reduce the relevance of 'residual explanation' due to differing national understandings as to what 'sustainable development' really is, and how governments should pursue it. In the present context, national commitments to implement the RES-E Directive (as an integral part of the EU's overall commitment to the Kyoto Protocol for reducing greenhouse gas (GHG) emissions) provides a strong common reference point for assessing systemic differences. Given eight test cases that differ along significant 'national' dimensions - geographical, cultural, political and institutional - what can we learn about the effectiveness of policy implementation if we 'probe' each case with a standardized obligatory 'stimulus'?

By choosing the so-called 'RES-E Directive' (2001/77/EC of 27 September 2001) as this stimulus, we have selected an SD policy goal that places a strong obligation for compliance on EU Member States and associated states. As we shall see below, the states have negotiated individual 'indicative targets' for RES-E, measured as a given share of the overall consumption of electricity in 2010. This means that each of the eight countries chosen here can be assessed as to its progress and results on specific targets, agreed within a common policy framework. While the overall goal of the Directive is to achieve an aggregate target for the EU-15 of 22 per cent RES-E by 2010, the indicative targets for the Member States vary between 5.7 per cent (Luxembourg) to 78.1 per cent (Austria). Given that the Directive also stipulates which RES-E technologies qualify for fulfilling target levels, we have a framework for assessing implementation that is common for the eight cases selected here.

Finally, the relationship between the Directive and the discourse on sustainable development is explicitly stated, thus allowing for straightforward comparisons with our earlier, more general, studies. The opening paragraph of the Directive reads as follows:

Whereas: (1) The potential for the exploitation of renewable energy sources is underused in the Community at present. The Community recognises the need to promote renewable energy sources as a priority measure given that their exploitation contributes to environmental protection and sustainable development. 
Equally important, however, is the passage immediately following this:

In addition this [the promotion of RES-E] can also create local employment, have a positive impact on social cohesion, contribute to security of supply and make it possible to meet Kyoto targets more quickly. (OJEC 2001: L283/33)

In short, the RES-E Directive aims to reconcile the Gothenburg and Lisbon agendas by coincidentally addressing economic concerns (local employment and security of supply), social concerns (employment and social cohesion) and environmental concerns (reducing GHG emissions). The degree to which implementation of the Directive satisfies these concerns, either individually or in interaction, is, of course, open to considerable discussion. Drawing out these nuances will be an important part of the analysis, given that virtually all interest thus far has focused on the indicative targets and other goals of the Directive rather than on a 'balanced' achievement of sustainable development.

\section{The RES-E Directive}

The ultimate form and content of the RES-E Directive was negotiated within a context of increasingly difficult demands on electricity production and consumption in Europe. The consumption of electricity was growing for all sectors; the proportion of electricity produced from fossil fuels was increasing; the supply of fossil fuels was increasingly dependent on foreign imports; these imports were simultaneously becoming more expensive and more insecure; and, finally, demands for curbing GHG emissions from existing generating systems were becoming increasingly critical, politically, legally and economically (to meet Kyoto obligations). Something had to be done - and it had to be done within a highly complex policy setting of competing values, goals and interests. Given the relatively limited and relatively standardized technological parameters related to the production and consumption of electricity, as well as the broad and crucial relevance of electricity for both households and jobs, the potential multidimensional pay-off of an electricity-specific initiative was apparent.

As documented by Lauber (2002, 2005) and Rowlands (2005), the process for agreeing the Directive can be seen as a classic case of 'compromise decision-making' between the EU Commission, the Council of Ministers and the Parliament. The most outstanding issues for negotiation (over a five-year period, from November 1996 to October 2001) were: (1) the definition of 'renewable'; (2) the type and specific levels of 'targets'; and (3) the question of 'harmonizing' a common promotion scheme for the EU as a whole (Rowlands 2005: 967-72). These issues capture the most 
important goals of the Directive, and, taken together, establish a succinct baseline framework for assessing implementation efforts across the eight case studies.

\section{What are 'renewable energy sources'?}

While it is relatively easy to identify non-renewable energy sources (since they tend to dominate all existing energy systems, and are extensively documented as to relative finitude), it is much more difficult to reach agreement on what could and should be understood as a 'renewable' resource. A potential list of such resources could, of course, be extensive indeed, since numerous future possibilities for alternative electricity generation exist at any one time. In deciding which types of resource to include in the "promotion package' of the Directive, it was thus necessary to stipulate the instrumentalist criteria by which promotion could be carried out and assessed.

This is particularly important in an EU context, since the body entrusted with formulating and eventually monitoring the progress of implementation - the European Commission - has a primary responsibility for realizing the overriding goal of the Single Europe Act of 1986: the achievement of a truly functional trans-European market. Any policy initiative that might create distortions of the market - however well intended - is in this context inherently 'problematic' for the Commission. Given the multifaceted value structure related to the task of promoting renewable (alternative) energy systems, along with the clear sociocultural 'embeddedness' of the existing energy system, this posed a major policy dilemma for the Commission: how to achieve the diverse and potentially conflicting goals of the task through cost-effective market incentives alone.

According to Rowlands (2005), this original 'bias' in the role of the Commission led to two crucial aspects of the resulting Directive: (1) a focus on those renewable technologies deemed most amenable to economic incentives; and (2) a strong emphasis on 'tradable green certificates' (TGCs) as the instrument of choice by the Commission for promoting RES-E on a Community-wide basis. Both aspects were, however, openly confronted, debated and modified over the five-year negotiation period. We return to the question of instruments below, and focus here on the choice of technologies designated as 'renewable' within the scope of the Directive.

Article 2 (a) of the Directive defines 'renewable energy sources' as 'renewable non-fossil energy sources (wind, solar, geothermal, wave, tidal, hydropower, biomass, landfill gas, sewage treatment plant gas and biogases)' (OJEC 2001: L 283/35). The 'alternative' status of these sources to fossil fuels is relatively straightforward, and the first five - wind, solar, 
geothermal, wave, tidal - are also manifestly 'renewable'. The remaining five, however, apparently generated considerable debate among representatives of the different EU institutions and external participating interests.

The first issue that had to be clarified was the status of hydropower. No one disputed, of course, that hydropower was a well-established renewable source of electricity. What did create controversy, however, was, on the one hand, the desirability of further promoting large-scale hydro in Europe with respect to concerns for nature conservation; and, on the other, the very possibility of developing effective market-related promotional instruments on the scale necessary for initiating, funding, constructing and running large hydropower plants. For both of these reasons, there were apparently no serious propositions specifically to designate large-scale hydro as a promotional priority. At the same time, however, those countries with existing significant proportions of hydro-generated electricity were clearly not willing to disregard the enormous investments already made in this particular source of RES-E (see Table 1.1).

The ultimate result was a rather fascinating compromise. Whereas largescale hydro would be included in the calculation of baselines for determining targets, there would be nothing in the Directive that would specifically designate further large-scale hydro development as a promotional goal. Equally important, however, is the fact that the Directive does not exclude large-scale hydro either. An earlier proposal to differentiate between 'largescale' and 'small-scale' as being over or under $10 \mathrm{MW}$ of output thus remains in the 'aura' of the Directive - but not in the text. As we shall see in the case studies, the issue has very different connotations for the different Member States (and particularly for Norway), emerging as a key feature of both the substantive conditions for pursuing national targets and of specific barriers to RES-E promotion related to the nature of the 'dominant energy system' (DES) in each case. At present, however, it is sufficient to highlight the issue as typical of the numerous 'unresolved and potentially controversial' aspects of the Directive.

A second major challenge for a consensus on the meaning of 'renewable' was related to biomass. The issue here was primarily what should, and should not, be included as a 'biomass' source. The definition adopted (Article 2 (b)) stipulates that biomass 'shall mean the biodegradable fraction of products, waste and residues from agriculture (including vegetal and animal substances), forestry and related industries, as well as the biodegradable fraction of industrial and municipal waste'. Without going into detail, we can simply point out that the major debates here focused on the general status of the different waste materials (as to both type and source), as well as on the issue of 'combustion' (generating electricity from the incineration of different waste stocks) (Rowlands 2005: 968). More 


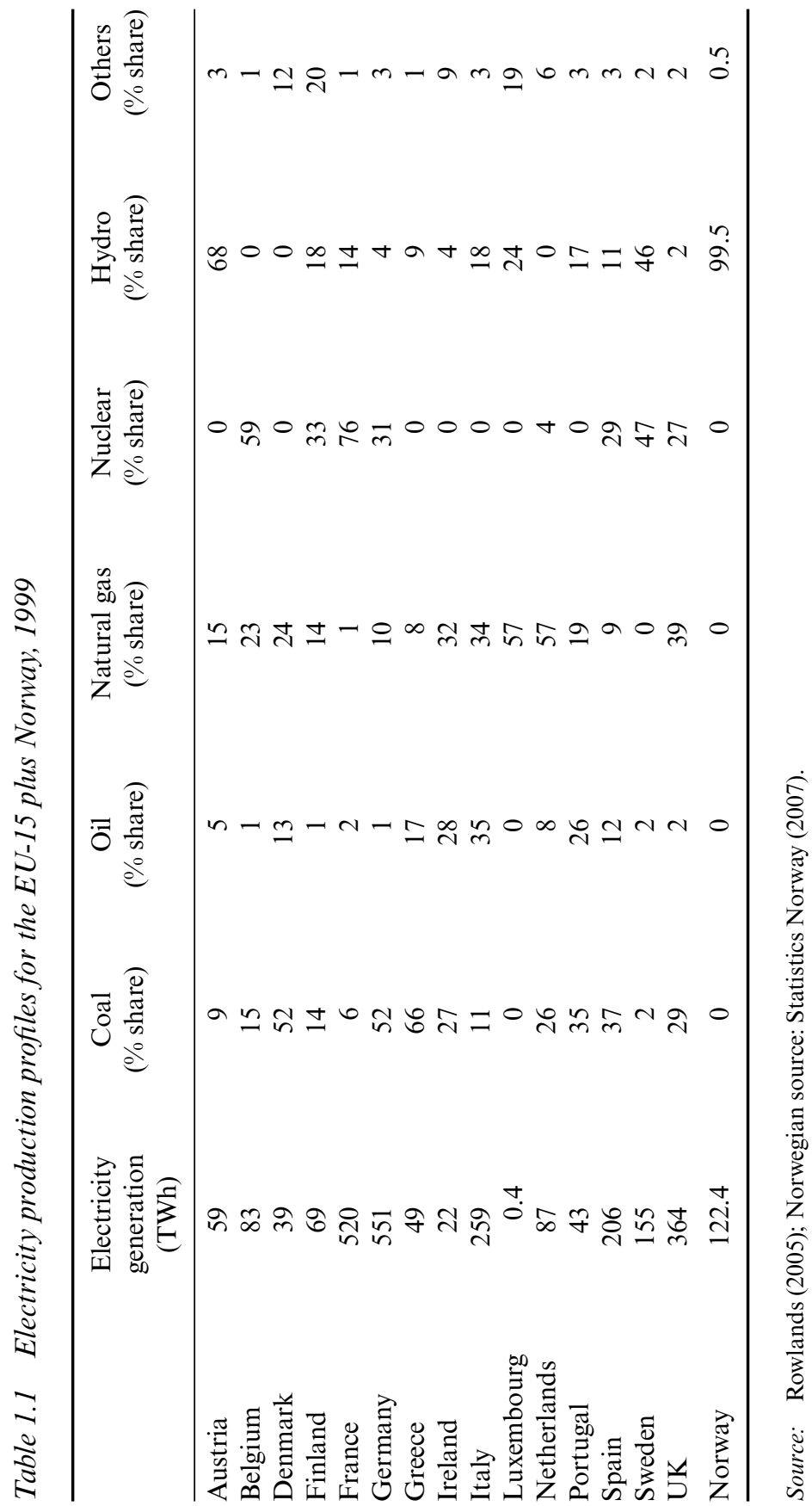


critically for certain countries (particularly Ireland and Finland), it was also ultimately decided to exclude peat as a renewable source.

Finally, there is one additional issue that was apparently resolved by fiat at the outset, leaving nary a trace of conflict in the final document: nuclear energy. One might have thought that countries such as France, Belgium and Sweden, with respectively 76,59 and 47 per cent shares of electricity production from nuclear power (Table 1.1), would have raised a similar issue for nuclear as was raised for large-scale hydro. There is no evidence that this was the case, however, so we must assume it was simply a 'dead issue' from the start. As we shall see, however, the nuclear industry is a key actor in the dominant energy systems of these countries, and the role of nuclear vis-àvis climate change and alternative energy has clearly affected the implementation of RES-E in at least one of our case studies: Sweden.

\section{The nature and onus of national targets}

The nature and desirability of targets as a steering device for policy implementation is a key aspect of policy analysis (Cohen 1999; Eden 1996; Hajer 1995; Héretier 2002; Smeets and Wetering 1999; Stavins 2002). While governments and national ministerial bureaucrats tend to shun targets, environmental organizations and supranational bureaucrats tend to embrace them. In the case of the RES-E Directive, the issue was not whether to have targets or not, but rather the type of targets to be established. The White Paper on 'Energy for the future' (CEC 1997) - which constituted a general framework and reference point for the preparation of the RES-E Directive - had proposed a target of 12 per cent RES as share of overall energy consumption by 2010. It had also suggested a target of 23.5 per cent RES-E for the same year (Rowlands 2005: 969).

In the course of the negotiations on the Directive, the issue of targets quickly focused on three questions: (1) the type of target - 'binding' (with designated sanctions) versus 'indicative' (with 'softer' forms of chastisement); (2) the level and timeline for an overall RES-E target for the EU-15 as a whole; and (3) the target levels for the individual Member States. Briefly, the outcomes on these three questions were as follows.

(1) The Directive stipulates only indicative targets. In contrast to other areas of conflict-compromise, however, the different perspectives on the issue were integrated into the language of the Directive itself. In introductory Clause 4 it is noted that the European Parliament had adopted a resolution (on 30 March 2000) which 'underlined that binding and ambitious renewable energy targets at the national level are essential for obtaining results and achieving Community targets'. Further, in introductory Clause 7 - which stipulates a review of progress on the indicative targets by the Commission in 2010 - it is explicitly stated that 'If necessary for the 
achievement of the targets, the Commission should submit proposals to the European Parliament and the Council which may include mandatory targets.'

These passages clearly reflect the dominant opinion of the Directorate General for Transport and Energy (DG TREN), the directorate responsible for the implementation of the RES-E Directive. Rowlands (2005: 969) cites an interview with the commissioner then responsible for DG TREN (Loyola de Palacio) as stating that 'she would have preferred to propose binding targets, but that she had been forced to abandon the plan in the face of stiff resistance from Member States'. Rowlands further indicates (ibid.: 970) that one of the main reasons why nearly all of the Member States opposed binding targets was that the levels actually negotiated for each Member State were perceived to be very ambitious. In short, the targets, though 'only' indicative, were clearly intended to imply an onus which is 'stronger than simply "suggestive"' (ibid.: 969).

(2) With respect to the overall target for the EU-15, the figure of 22.1 per cent RES-E was maintained from the earlier documents, with the date of achievement set at 2010. It is important to point out that the percentage in question is the proportion of consumption of RES-E as a proportion of 'gross national electricity production' (that is, 'autoproduction, plus imports, minus exports' (Article 2 (d)). It was also later stipulated that the ten accession countries were to transpose and comply with the Directive, but with lower global and national targets. The overall target for the new Member States (EU-10) was set at 11.1 per cent RES-E consumption by 2010, and indicative targets were negotiated for each new Member State in the Accession Treaty (OJEU 2003). The recalculated global target for the EU-25 was then set at 21 per cent. ${ }^{1}$

(3) As indicated, each of the EU-15 Member States negotiated indicative targets to be reached by the end of the initial period of implementation, 2010. The targets, as shown in Table 1.2, were appended as an annex to the Directive, with important qualifying footnotes for six of the 15 countries: Italy, Luxembourg, Austria, Portugal, Finland and Sweden. We need not go into detail on the individual targets here, since the relevant issues will be treated in the case studies. It is, however, interesting to note that the footnotes clearly indicate attempts by Member States to introduce the type of nationally specific contextual factors that are the focus of the present study.

\section{Harmonization of Community-wide support schemes}

The final issue that created considerable debate in the adoption process was whether there should be an attempt to standardize support schemes across the 15 Member States and, if so, what scheme or schemes this would involve. As described by Rowlands, the major discussion here focused on 
Table 1.2 Levels and targets of renewable electricity production/consumption, EU-15 plus Norway, 1997-2010

\begin{tabular}{lccc}
\hline & $\begin{array}{c}\text { Renewable electricity } \\
(\text { TWh), 1997 }\end{array}$ & $\begin{array}{c}\text { Renewable electricity } \\
\text { as a percentage of } \\
\text { total electricity, } \\
1997\end{array}$ & $\begin{array}{c}\text { Renewable electricity } \\
\text { target as a } \\
\text { percentage of total } \\
\text { electricity, 2010 }\end{array}$ \\
\hline Austria & 39.05 & 70.0 & 78.1 \\
Belgium & 0.86 & 1.1 & 6.0 \\
Denmark & 3.21 & 8.7 & 29.0 \\
Finland & 19.03 & 24.7 & 31.5 \\
France & 66.00 & 15.0 & 21.0 \\
Germany & 24.91 & 4.5 & 12.5 \\
Greece & 3.94 & 8.6 & 20.1 \\
Ireland & 0.84 & 3.6 & 13.2 \\
Italy & 46.46 & 16.0 & 25.0 \\
Luxembourg & 0.14 & 2.1 & 5.7 \\
Netherlands & 3.45 & 3.5 & 9.0 \\
Portugal & 14.30 & 38.5 & 39.0 \\
Spain & 37.15 & 19.9 & 29.4 \\
Sweden & 72.03 & 49.1 & 60.0 \\
UK & 7.04 & 1.7 & 10.0 \\
Norway & 111.4 & 96.7 & 90 \\
Community & 338.41 & 13.9 & 22.0 \\
total & & & \\
\hline & & & \\
\hline
\end{tabular}

Source: Rowlands (2005); Norwegian source: MoPE (2007).

three major instruments: tradable green certificates (TGCs); feed-in tariffs (FITs); and different forms of 'tendering' (2005: 971). (See Table 1.4, with textual comments, below.) The Commission was originally strongly committed to the prospect of immediately introducing harmonization through some form of tradable certificates. The rationale was that this system corresponded most closely with the principles of the Single Market, and, in fact, gave the best promise of achieving the adopted targets. Commission representatives apparently argued directly against feed-in tariffs in this context, clearly feeling that the use of feed-in support mechanisms compromised prohibitions against state subsidies.

The Commission was, however, met by considerable resistance in both the Parliament and sections of the Council of Ministers, and was gradually forced to alter its stance. Key Member States lined up on both sides of a major divide between TGCs and FITs, with Italy and the UK pushing for 
the former, and Germany, Denmark and Spain strongly supporting the latter. The Parliament was also more partial to FITs, so the result was a standard EU stand-off and compromise. The notion of an immediate harmonization regime was dropped in lieu of a five-year period where the Member States could pursue different paths and solutions in fulfilling the indicative targets.

In contrast to the original position of the Commission, however, the Directive included a separate paragraph (Article 4.1) which specifically opened the possibility of governmental support schemes that, though deviating from basic principles of the EU Treaty (Articles 87 and 88, regulating governmental intervention in the market), contributed positively to the objectives of both Article 6 of the Treaty (integrating environmental concerns to promote sustainable development) and Article 174 (on environmental policy). Finally, Article 4.2 of the Directive assigned the Commission the task of monitoring and assessing the different support mechanisms over a five-year period, with the aim of presenting a report no later than October 2005. This report should, 'if necessary', be accompanied by a Community-wide 'framework' for promoting RES-E. The outcome of the negotiations on this point was in general viewed as a significant step in the direction of raising the status of environmental concerns vis-à-vis freemarket concerns within the EU.

\section{Further issues of relevance}

Beyond the three major areas of contention and compromise covered by Rowlands, there are three other issues in the Directive of direct concern for the present analysis: Article 5 on 'Guarantee of origin'; Article 6 on 'Administrative procedures'; and Article 7 on 'Grid system issues'. Each of these issues has, in one way or another, figured directly in the varying implementation experiences of the cases covered here.

Article 5 of the Directive addresses an issue of crucial importance for the tradable certificate model of RES-E promotion: establishing a system for guaranteeing the renewable status of energy produced and marketed as RES-E. The six paragraphs of the article set up specific institutions and procedures for certifying the validity of RES-E both within and across Member States. Paragraph 4 of the article also stipulates that Member States can be compelled to recognize and honour guarantees of origin from other states, as long as the original certification is carried out in an 'objective, transparent and non-discriminatory' fashion. It is also interesting to note that the article stipulates that certificates from hydroelectric sources must indicate the capacity of the installation, thus allowing (again indirectly) for a distinction between RES from large-scale and small-scale hydro installations. 
Article 6 of the Directive is addressed to 'Administrative procedures'. Here the purpose is one of active intervention to: (1) reduce the 'regulatory and non-regulatory barriers' to an increase in RES-E; (2) streamline and expedite procedures for licensing RES-E at the 'appropriate administrative level'; and (3) ensure that the existing authorization rules are 'objective, transparent and non-discriminatory, and take fully into account the particularities of the various renewable energy source technologies' (Article 6.1). The Member States are also instructed to publish evaluation reports (no later than October 2003) that outline the progress made with respect to: coordination between the relevant procedures of the different administrative bodies; the drawing up of possible guidelines for the three initiatives listed above, and the feasibility of introducing a 'fast-track planning procedure' for RES-E producers; and the designation of specific authorities to act as mediators in disputes between issuing authorities and applicants (Article 6.2).

Finally, Article 7 addresses 'Grid system issues'. Here the purpose is to anticipate technical, legal and financial barriers to an effective integration of RES-E into existing grid structures. Recognizing at the outset that the existing system clearly favours established interests and actors, the purpose is to ease the way, within foreseeable limits and possibilities, for more rapid and effective grid integration. Specific initiatives are set forth in seven subparagraphs, and Member States are instructed to include a section on progress in this area in the reports stipulated for 2003 under Article 6.

\section{Focusing the goals of the RES-E Directive}

In sum, the RES-E Directive sets forth relatively strong expectations for Member States with respect to:

- the implementation of effective support schemes to meet the indicative targets for RES-E consumption by 2010;

- the introduction of a working system for issuing and accepting 'guarantees of origin' for RES generation;

- the general removal of administrative barriers to a more effective authorization of RES-E projects; and

- the removal of technical, economic and legal barriers to grid access for RES-E.

These four objectives constitute the major standards for any assessment of the implementation of the RES-E Directive. They were presented and discussed at the outset of the SUSTEN project, and served to provide initial empirical focus across the selected eight countries. The aim of the project became, however, more analytically challenging as we delved deeper into 
both the theoretical premises of the EU discourse and the specific types of research that, at that juncture (2003-4), were addressing the implementation problematic. Having made a thorough check of the programmes and projects initiated within both the 6th Framework Programme (DG Research) and the Intelligent Energy Europe Programme (IEE) (which was specifically designed to provide knowledge for improving the promotion of RES), we realized that the dominant view of the implementation challenge for RES-E within the Commission was strongly focused on what we came to refer to as the 'techno-market approach'. This orientation gradually led us to develop an alternative, supplemental approach: one built on the conviction that the techno-market model, while clearly capturing major aspects of the implementation problematic on a more abstract and rationalistic level, was at the same time neglecting - and even 'suppressing' what we believed to be crucial 'contextual' variables within the individual national settings. We also anticipated at the time that the knowledge and insights being produced by the dominant approach would not provide the necessary insights to overcome barriers to the development of the type of consensual, Community-wide promotion scheme that the Commission clearly aimed at, and that is presented in the Directive as the most desirable goal from 2005 onwards.

As matters turned out, the summary assessment by the Commission in 2005 led to the conclusion that the situation was premature for the introduction of a Community-wide scheme, and that national aberrations of the techno-market premises were at least one of the reasons for the inertia (CEC 2005). In the following section we elaborate on the reasoning that led us to adopt an alternative, supplementary approach to the dominant techno-market model, and present a brief justification for our choice of the paired concepts 'path dependence'/'path creation' as promising theoretical constructs.

\section{PROMOTING RES-E: THE CHALLENGE OF 'GROUNDING' THE TECHNO-MARKET MODEL}

During the run-up to the adoption of the RES-E Directive, the EU Commission supported a major project on the 'Renewable Energy Market Accelerator' (REMAC 2000). The project was carried out in cooperation with the International Energy Agency (IEA) and the government of Switzerland, and it clearly influenced mainstream thinking within the Commission. Dissemination of its assessments of the major RES technologies (wind, biomass, photovoltaics (PV), solar-thermal, geothermal and small-scale hydro) underpinned the Commission's original position on 
the draft Directive, and the publication of the project's final report in 2003 (OECD/IEA 2003) coincided with the deadline for transposing the Directive (October 2003).

A 'foreword' to the report by the Executive Director of the IEA, Claude Mandil, gives clear expression to the general conviction of the project, as well as identifying its principal addressee:

This study presents policy makers, managers and the interested public with relevant information on those renewable energy technologies that have entered the electricity market, but are not yet in the mainstream of the energy sector. Policy makers will play a vitally important role in capturing the future potential of these technologies, as government policies will determine their further technological development, cost reduction and competitiveness. This publication suggests that by focussing market supports on those situations where renewables are closest to [being] competitive, policy makers can accelerate the process of bringing renewables into the mainstream, while reducing the costs of doing so. (OECD/IEA 2003: 3)

As key instruments of this orientation, the report presents a matrix of 'focal points for policy intervention in renewable energy technologies', accompanied by a model of a posited 'virtuous cycle in a supportive policy environment'. The matrix of focal points for intervention is constituted by a cross-classification of two dimensions: (1) a set of four linear steps: basic research, applied research, market introduction and sustained market integration; and (2) a set of 'opportunities for improvement of technical and economic performance' (OECD/IEA 2003: Table 1, p. 17). As for the 'virtuous cycle', this portrays the dynamic of the approach as a mutually supportive interaction between 'technology development' and 'market deployment', leading to a progressive 'industrial development' of both the quantity and quality of RES technologies (Figure 1.1).

It was this general perspective that led us at the outset of the SUSTEN project to speak of the standard 'techno-market approach'. It was an approach that we found dominant in virtually all of the major research projects focusing on the promotion of RES-E at the time. ${ }^{2}$ It was also an approach that previous research experience had led us to believe would be at best partial, and at worst counterproductive, as a practical solution for achieving the aims of the Directive. We found, moreover, support for this interpretation within the REMAC project itself. In a forthright recognition of the techno-market bias of the approach, the authors of the final report state:

[The] virtuous cycle functions in a different manner for each of the renewable technologies, based on the specific maturity of the technology and how far it has progressed in markets. These differences between the six renewable technologies 


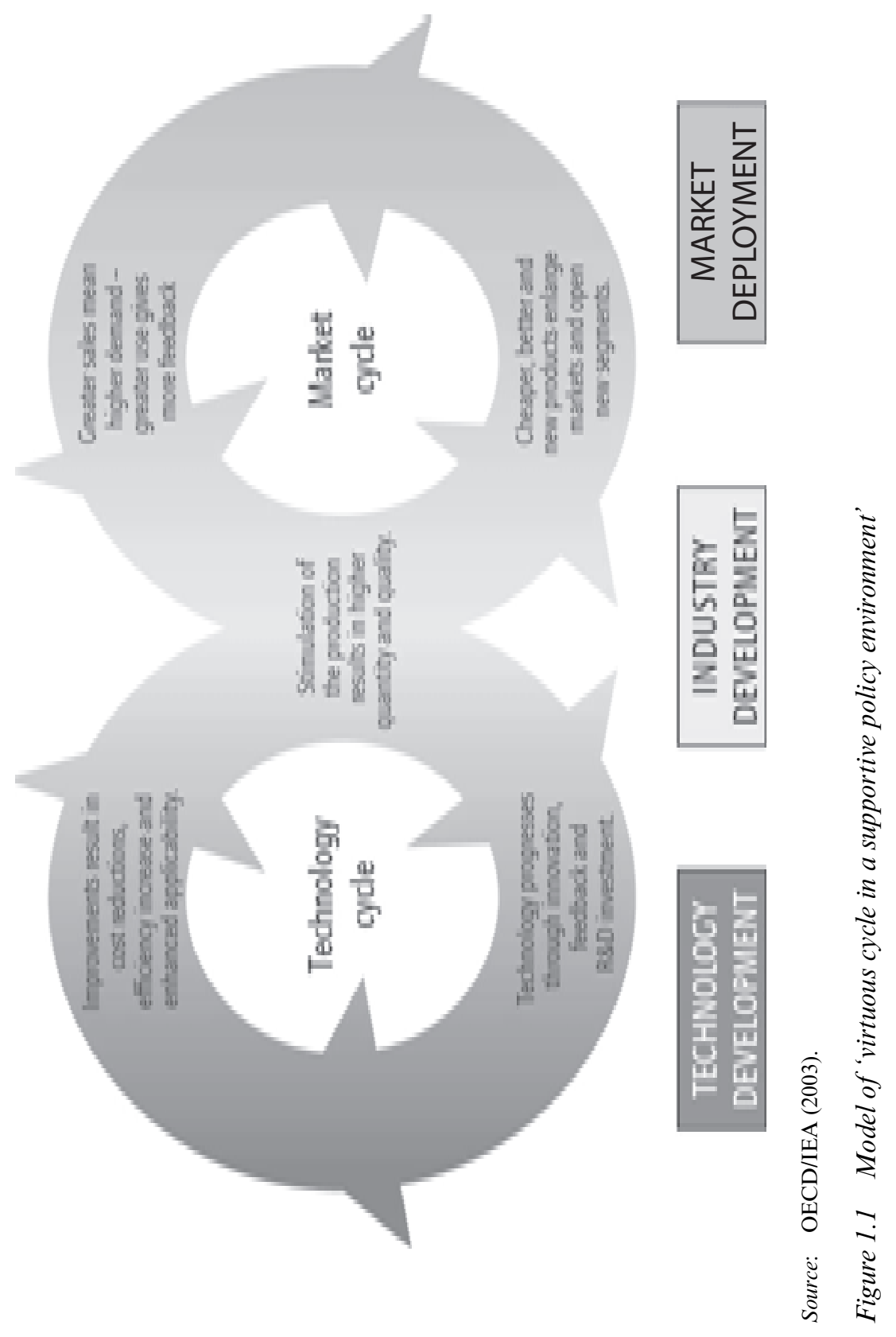


are crucial . . Thus, while policy makers should recognise the broad similarities of renewables, they must also realise that to affect market growth and competitiveness, they need to address specific technologies in the context of local conditions ... The technology 'learning curves' [highlighted in the report] translate the complex relationships among technology, industry and market into a curve of declining costs. However, these curves only interpret the input and output of the learning system; they do not explain the process going on within it. (OECD/IEA 2003: 14-15, emphasis added)

The report thus openly acknowledged a need for 'grounding' (contextualizing) the crucial techno-market parameters. Yet we found at the time no major research initiatives designed to provide such knowledge, despite the fact that the EU Commission was itself in the process of politically acknowledging the type of barriers in question. In the preparatory phase of the initial evaluation report mandated by the Directive (2003-4), it was already clear that the Commission was being confronted by the residual factors affecting the techno-market approach. This was made manifest in the report submitted to the Council and Parliament in May 2004, where it was concluded (on the basis of both individual-country reports and an overall assessment) that the prospect of a Community-wide promotional scheme for RES-E by 2006 was not realistic, and that a major reason for this was resistance from both national political authorities and dominant energy actors in the Member States.

The language of the Commission report is relatively straightforward. After noting that it was already clear that the EU as a whole would fall about 4 percentage points short of the global target for 2010 ( 22 per cent), the report states: 'One of the reasons for this discrepancy appears to be that a number of Member States have not yet introduced active policies in line with the targets that they adopted' (CEC 2004: 4). Furthermore, it is stressed in the report that:

With a framework of Community legislation in place, it is to Member States that responsibility falls for ensuring that the agreed targets and measures are, in fact, implemented on the ground. This will require a wide range of national actions, including efforts to ensure that established firms in the energy supply industries pay a share of the costs of promoting renewable energy. (CEC 2004: 6, emphasis added)

It was in anticipation of just such a result that the SUSTEN research team moved, in its opening phase, towards a more comprehensive contextual approach to the implementation challenge. Building on experience from earlier comparative studies, the goal was to develop a conceptual frame that would coincidentally acknowledge and supplement the technomarket approach. The approach outlined below, developed over a series of 
project workshops, is the result of this effort. It builds on the related ideas of 'path dependence' and 'path creation'. 3

\section{Confronting the Inertia of Existing Energy Systems}

As indicated above, a review of the major $\mathrm{R} \& \mathrm{D}$ projects looking at the promotion of RES-E in Europe indicated a strong bias towards either: (a) improving technological performance (along a number of different parameters), or (b) improving market penetration and learning. With very few exceptions, other types of variables - geographical, historical, institutional, cultural, normative etc. - were treated as 'residual' factors which clearly could have an impact on implementation, but which were not systematically included in the analyses. There was very little specific focus on the potential explanatory weight of such factors within the individual settings; nor was there any attempt to assess the influence of the factors across settings. SUSTEN was thus designed to provide systematic knowledge on how the RES-E task was being perceived and pursued within specific national contexts.

Given the clear possibility that numerous barriers to increased production and consumption of RES-E lie, not in techno-market factors themselves, but in variables that condition techno-market effects, the project has aimed to bring these variables to light so that they can be approached with more contextually specific instruments and eventually integrated into more robust instrumental models. The approach thus distinguishes between two types of 'conditioning variables' with respect to the dominant promotional model: (1) structural variables conditioning energy-system resistance (inertia) to RESE - path dependence; and (2) contextual variables conditioning the actual introduction and integration of RES-E in specific regional-local settings path creation. The variable categories can then be portrayed as a relatively simple model for improved RES-E implementation (Figure 1.2).

By the term 'structural variable' is meant a conditioning influence that is traceable to patterns of interdependent material, social, cultural, ideational and normative factors that have become relatively 'fixed', and relatively resistant to change, within the collective activity of the community in question. The use of such variables is most common in classic sociology, the best known being Karl Marx's concept of 'the means of production'; the complementary ideas of 'Gemeinschaft/Gesellschaft' employed by Max Weber and Ferdinand Tönnies; and Emile Durkheim's 'division of labour'. The underlying logic of these constructs is that the relationships among the designated categories of the chosen system (whether classes, institutions, ethos or collective actors etc.) are - as a result of the postulated functional interdependences of the model in question - demonstrably manifest in terms of 


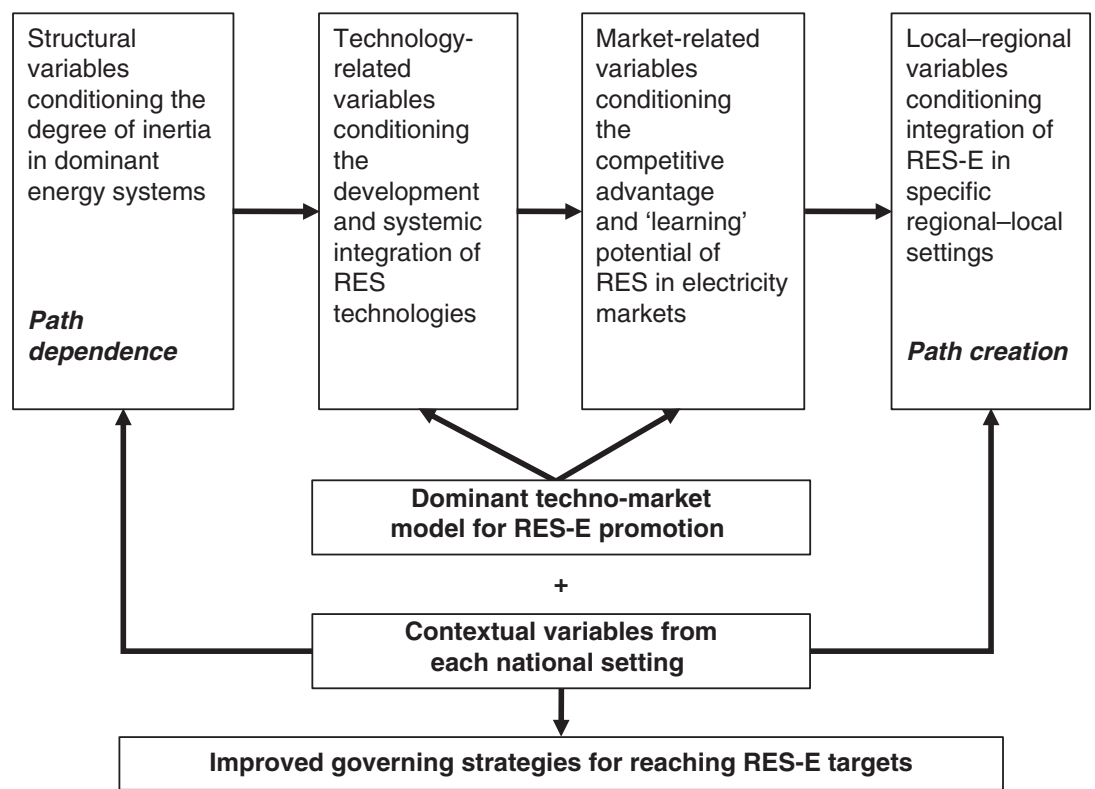

Figure 1.2 The SUSTEN model for analysing the promotion of RES-E

predictable sets of beliefs, values, attitudes and behaviour on the part of the individual and collective actors within the system. They exert, in other words, a 'structural' impact on behaviour that is systematic enough to allow for empirical analysis and prediction, and that creates a demonstrable inertia in the system.

Given the focus of analysis here - probing the degree of resistance to the introduction and integration of alternative energy systems - we are primarily interested in those collective actors and interactive patterns that 'structure' the 'energy arena' into which new RES-E technologies and applications must be introduced, survive and eventually become part of a new structure. The relationship between technology and market thus emerges as strongly embedded in the mediation of particular nature-energy relationships (through cultural ethos, historical decisions, political ideology etc.). To paraphrase the well-worn imagery of Marshall McLuhan (1964), the 'medium' within which RES-E is to be integrated (the existing 'dominant' energy system) is viewed as a crucial part of the 'message' necessary for more successful promotion and integration. ${ }^{4}$ The individual characteristics of each national energy system are seen as formed by specific structural-institutional 'journeys', the 'paths' of which are diversely 'rutted' and diversely resilient to 'rerouting'. 


\section{Specifying Path Dependence and Path Creation}

It was to capture these particular conditioning effects - and the challenge to overcome them - that we chose the terms 'path dependence' and 'path creation'. The choice serves as conceptual shorthand for expressing the degree of 'inertia' and 'embeddedness' in the different nationalregional-local energy systems. ${ }^{5}$ The simple assumption is that, at the point of substantive inception of RES technologies into the energy system, there exists a 'dominant energy system' (DES), the nature of which is strongly influenced by the exigencies of its particular historical development. The DES is thus viewed as a constellation of energy-related actors - investors, resource exploiters, market facilitators, energy producers, energy-system managers, public regulators, adaptors, mediators, end-users etc. - which has emerged within contingent conditions, and which exerts systemic (structural) influence on the potential for change.

In addition to capturing the essence of contextual restraint with a relevant general analogy (the image of established 'paths' and the potential for alternative future 'paths'), the concept of path dependence allows us to link up with one of the many discourses associated with what has become a very disparate and controversial idea. We refer to the usage of the concept by 'evolutionary' and 'institutional' economists in connection with 'market lock-in' through 'increasing returns to adoption'. This particular subdiscourse has its origin in technology-market interactions, and has been employed by Garud and Karnøe $(2001,2003)$ with specific reference to RES promotion.

The concept also allows us to conceptualize the integration of RES-E as a challenge of 'path creation', where the barriers inherent in path dependence must be overcome by altering the defining 'media' of the dominant energy system. The higher the degree of path dependence in any given DES, the more resistant the system is to promotional initiatives for developing and deploying 'new' RES-E technologies. Understanding why and how energy path dependence has developed in each case thus becomes a principal aim of the SUSTEN project.

It is important to stress at the outset, however, that the notion of path dependence is used in very different ways, with very different interpretive connotations. This applies to the essential meaning of the concept, as well as to a broad diversity of applications across disciplines. In order to establish a common reference within the SUSTEN project, we employed a relatively simple 'taxonomy of path dependence' provided by two of the leading critics of the concept: Liebowitz and Margolis (1995, 1998). In trying to 'salvage' the essence of the idea - after seriously undermining the most common usage of the idea by economists, the so-called increasing 
returns to adoption' position - Liebowitz and Margolis propose the following differentiation: ${ }^{6}$

(1) 'First-degree path dependence' Defined as a 'minimal form of path dependence', this form is present 'whenever there is an element of persistence or durability in a decision'. It is the notion of crucial decisions - and the implications such decisions have for subsequent changes in choice of path - that is viewed as semantically essential: 'What we have today depends critically on the conditions that prevailed and decisions taken at some time in the past.' In contrast to the views below, there is no necessary 'error' or 'inefficiency' in the system. In this view, 'Path dependence does not harm; it is simply a recognition of durability': that is, a recognition of the necessity to come to terms with 'the brute facts of history'.

(2) 'Second-degree path dependence' Here, 'the inferiority of a chosen path is unknowable at the time a choice is made, but we later recognize that some alternative path would have yielded greater wealth'. There is thus 'a dependence on past conditions that leads to outcomes that are regrettable and costly to change'. This dependence is, however, 'not . . . inefficient in any meaningful sense, given the assumed limitations on knowledge'. It implies an awareness of the 'plasticity' of history, and a contention that some specific alternative path of interest could (in retrospect) have been better staked out.

(3) 'Third-degree path dependence' This form - the strongest (most volitional) type of path dependence - involves a claim that 'alleges the existence of remediable inefficiencies' at the time of decision-making. A crucial decision is made, in other words, where the path chosen is 'demonstrably' inefficient (or negative in some other way), but the actors choosing (and following) the path nonetheless fail to coordinate their actions in a 'better' manner. It is this type which (in the view of Liebowitz and Margolis, incorrectly) applies to the classic illustrative case of the QWERTY keyboard for typewriters. While the original choice of the keyboard was made to avoid the jamming of typing keys, its use in the path-dependence literature refers to a postulated inertia in the system whereby consumers of typing services are not willing to adopt an existing alternative system (the so-called 'Dvorak keyboard'), despite 'proof' that the alternative system is both more effective (faster) and cost-efficient. Actors continue along the path, because the 'returns' they get from 'adopting/adapting' are perceived as greater than the postulated increase in efficiency to be gained by a path change. ${ }^{7}$

Liebowitz and Margolis summarize the differentiations in their typology as follows: 
The three types of path dependence make progressively stronger claims. Firstdegree path dependence is a simple assertion of an intertemporal relationship, with no implied error of prediction or claim of inefficiency. Second-degree path dependence stipulates that intertemporal effects together with imperfect prediction result in actions that are regrettable, though not inefficient. Third-degree path dependence requires not only that the intertemporal effects propagate error, but also that the error was avoidable. (1998: 3)

Translating this understanding to the present problematic (as a 'working premise' for discussing the transition dynamics of RES-E promotion and integration), we can say that the three types point towards three levels of problem interpretation.

First-degree path dependence captures the essential notion underlying the core idea. The path dependence of the DES is here viewed as simply reflecting the contingent 'choices' made as to the major technologies of the system. The type of 'rationality' in question reflects a basic pragmatism involving, for example, three factors: (1) the natural-resource base of the technology; (2) the level of efficiency of the technology in exploiting the resource for electricity production; and (3) the market demand for electricity usage. Such an assumption makes no judgement as to the 'correctness' of the implied rationality. It is simply an intuitive explanation for why given constellations of resources, technologies and uses develop at a given point of time. The 'inertia' in question at this level is thus one of 'intertemporal continuity' (habit, routine), and of the 'structural' socio-economic relationships that sustain the inertia. In this view the emergent constellation of energy-technology paths gradually becomes identifiable as a 'dominant energy system', reflecting a historically determined ('embedded') contextual influence which can be fruitfully analysed as to the contingent information of the case.

Second-degree path dependence directs our attention to the possibility that the inertia in the DES is not merely a reflection of techno-market adaptation to existing material conditions, but can also be viewed now as 'problematic' in one way or another. The original choices leading to dependence are viewed as in some sense 'regrettable', though not necessarily as 'inefficient' in an economic sense. This perspective would open the way for an interpretation which views the original techno-market 'bindings' of the system as reasonable from the point of view of contemporary goals and choices, but potentially sub-optimal for any number of reasons now. The reasons why one would want to change the DES is an open question. It could be for ideological, technical, social or even market-related reasons. One finds in retrospect something 'wrong' with the original choices structuring the DES, which opens the way for a discussion as to whether the 'current regret' is a reasonable point of departure for change. 
This type of perspective could be relevant to any number of national, regional or local initiatives that aim to change part or all of the DES - but that are not specifically based on counter-claims to a given standard of efficiency. ${ }^{8}$ In the context of promoting RES-E, for example, different technological options can be advocated as alternative paths to the DES for reasons that do not rest solely, or even principally, on a notion of resourcemarket efficiency. These can be reasons of social organization (to maintain the existence of communities that are not serviceable by the DES); nature conservation (for moral-philosophical reasons); or overarching normative goals (to achieve sustainable development). More specifically, seconddegree path dependence could involve change directed towards achieving stipulated EU goals on security of supply and fulfilling the Kyoto commitments. When reasons such as these are posed, second-degree path dependence indicates that the inertia and conflicts over change will be conducted within the value framework of the critical position: that is, driven by claims that the existing path is 'regrettable' - though not necessarily 'inefficient' in a market-equilibrium sense.

Finally, with third-degree path dependence, we open the way for an important perspective on the history of attempts to introduce RES into the DES. When Liebowitz and Margolis indicate that the key criterion for third-degree dependence is that the 'error' in the dependence is not only regrettable now, but was 'avoidable' then, they mean that it was avoidable because other, more 'efficient', paths were both possible and proposed. Although the logic here becomes very complex (particularly since the authors claim to deny the empirical basis for the best-known cases underlining the 'increasing returns to adoption' approach), there would nonetheless seem to be an interesting application of the 'third degree' with respect to the SUSTEN problematic. As stated elsewhere by the authors:

In third-degree path dependence, sensitive dependence on initial conditions leads to an outcome that is inefficient - but in this case the outcome is also remediable. That is, there exists or existed some feasible arrangement for recognizing and achieving a preferred outcome, but that outcome is not obtained. (Liebowitz and Margolis 1995: 207, original emphasis)

If the core of our approach is accepted as an attempt to profile, critically analyse and eventually supplement the techno-market approach to RES-E promotion, we can - within the logic of third-degree path dependence raise the question of what kind of 'efficiency' is currently underlying the overall promotional effort. Whereas first-degree path dependence points towards barriers related to the inertia and embeddedness of 'brute history', and second-degree path dependence points towards an analysis of barriers 
related to the institutional and power configurations that became 'structured' at crucial points of alternative energy-path decisions for the system, and that are still functional, the third-degree perspective allows us to assess the competing claims to 'efficiency' that currently infuse national debates on the 'best' technological RES-E alternative. The last perspective can also be expanded to shed light on the path-dependent effects related to a onesided research-and-policy emphasis on techno-market promotion, in contrast to the more contextually sensitive model proposed here. In this latter connection, we shall want to explore the implications of alternative notions of efficiency: most particularly the differences between 'mainstream' ideas of cost-benefit techno-market efficiency, versus both 'eco-efficiency' and 'eco-effectiveness'. ${ }^{9}$

In sum, the three perspectives together can provide crucial insights into the different institutional and resource-controlling parameters of each national energy system. This is clearly information of direct relevance for achieving RES-E 'path creation' in and through specific regional-local settings, but it is also of immediate importance for introducing alternative cost-benefit criteria into the ongoing debate on achieving a more effective 'general framework' for the European Economic Area as a whole.

\section{Mapping the Interaction between Path-dependent Energy Systems and the Promotion of RES-E}

On the basis of this general understanding of the meaning and relevance of path dependence/path creation for the instrumentalist goals of the project, the research project then proceeded to develop a common empirical focus for the analysis. Known internally as the 'research protocol', the purpose of the exercise was to provide similar information on the implementation of the RES-E Directive within and across the eight national systems chosen. The aim was to provide substantive information on the RES-E 'storyline' for each national case (thus guaranteeing 'idiographic' insight), so that the information could then be used to analyse the effects of path dependence on the more general techno-market promotion efforts being sponsored by the European Commission (thereby expanding the general robustness of more 'nomothetic' generalizations). ${ }^{10}$

\section{Four key aspects of the implementation problematic}

Towards this end, the protocol stipulated four types of information:

(1) The general profile of the 'dominant energy system' (DES) with respect to the introduction of the most 'advanced' new RES-E technologies: wind, biomass, photovoltaics, geothermal and small-scale hydro It was 
up to each team to profile those technologies that were most relevant to the goals of the RES-E, with emphasis on the following aspects:

(a) A brief description of the energy types that constitute the DES, and the natural conditions that gave rise to them.

(b) A brief history of the crucial decisions and major production factors that have determined the path development of the DES.

(c) An overview of the major actors of the DES at the time of RES inception, including: the major providers of DES electricity (whether private, public or mixed private-public actors); the major governmental bodies involved in the regulation and monitoring of the system; the major branch organizations for each technology; and the major consumer organizations or NGOs involved in the working of the system.

(d) A brief overview of the major constitutional, legal and administrative prescriptions that underlie and support the DES.

(e) A brief assessment of the system with respect to domestic versus imported electricity.

(f) A brief overview of the degree to which the major interests in the DES are reflected in partisan politics; that is, which parties are identified with which interests.

(g) A brief overview of how the system had 'processed' or 'reacted to' the development and possible introduction of the four RES technologies into the system. The vantage point here is the history of the alternative technologies up to the issuance of the RES-E Directive in September 2001. What are the major conflicts and alliances that have arisen around the development and phasing-in of the alternative technologies; and how has the 'inertia' of the DES affected the specific form and potential of the RES-E alternatives?

(2) A description of the governing mechanisms, institutions, strategic actors, programmes and policy instruments promoting RES-E goals and targets In line with nearly all approaches to the problematic in EUfunded research, emphasis should be placed on initiatives directed towards overcoming technology and market barriers. What is being done by whom to increase the proportion of electricity from the major RES technologies, and how have these efforts been influenced (either hindered or promoted and integrated) within the dominant energy system?

(3) Viewing the implementation of RES-E as a crucial aspect of 'technological innovation for sustainable development', how has RES-E promotion been specifically connected to governmental efforts to achieve innovation for increased economic competitiveness? To what degree, in other 
words, have initiatives to achieve the goals of the RES-E Directive been related to and integrated with initiatives to promote innovation in industry and business? More specifically, are there any programmes or initiatives that specifically relate the RES-E goals to the more general goal of achieving a better integration of economic, social and environmental concerns within the European Community (as prescribed by Article 6 of the EU Treaty)? Such efforts could be identifiable in relation to several EU goals: improving security of energy supply; reducing GHG emissions (the Kyoto targets); promoting new employment opportunities; and promoting innovation for regional and urban development.

(4) Provide a brief overview of the four 'most interesting' regions/localities that illustrate the problems and potentials of phasing in the four RES technologies into locallregional electricity consumption, and provide a general assessment of the major barriers against, and major possibilities for, 'path creation' for RES-E within these areas.

Finally, in relation to the second task of providing a more general national 'storyline', the teams were also asked to provide their own general assessments of RES-E implementation.

These very general guidelines provided the common framework for the project, and it has been up to the project leadership to try to draw out the most relevant lessons for RES-E promotion efforts in Europe. So as to place this task in as timely a frame as possible, and to relate the individualcountry studies to overall developments in Europe, we conclude our introduction with a brief overview of: (1) promotional instruments and barriers to RES-E on a general level; and (2) the status of RES-E implementation as assessed by the EU Commission itself.

\section{BARRIERS, INSTRUMENTS AND RESULTS}

\section{The EEA Overview of Barriers and Instruments}

Coincidental with the adoption of the RES-E Directive, the European Environment Agency published a list of 'Barriers and obstacles to renewable energy deployment' (Table 1.3). The Agency expanded on the list by addressing the following questions to each of the barriers and obstacles identified (pp. 27-30):

- Political: How strong is political support for the renewable energy?

- Legislative: How accessible is the energy market to independent electricity producers? 
Table 1.3 Barriers and obstacles to renewable energy deployment

\begin{tabular}{|c|c|}
\hline Barrier & Obstacle \\
\hline Political & $\begin{array}{l}\text { Lack of political motivation to support the market } \\
\text { initiatives needed for the development of renewables }\end{array}$ \\
\hline \multirow[t]{2}{*}{ Legislative } & $\begin{array}{l}\text { Lack of an appropriate legal framework and legislation } \\
\text { at EU and national levels that support the } \\
\text { development of renewables }\end{array}$ \\
\hline & $\begin{array}{l}\text { Difficulties with linking electricity or heat from } \\
\text { renewables into the existing electricity and heat } \\
\text { networks }\end{array}$ \\
\hline Financial & $\begin{array}{l}\text { Lack of appropriate financing for long-term financial } \\
\text { benefits }\end{array}$ \\
\hline Fiscal & $\begin{array}{l}\text { Renewable energy technologies suffer from distorted } \\
\text { competition from conventional energy sources (e.g. } \\
\text { coal, nuclear) in terms of final end-user prices }\end{array}$ \\
\hline Administrative & $\begin{array}{l}\text { Lack of practical support at the regional and local level } \\
\text { to stimulate development of renewable energy projects }\end{array}$ \\
\hline Technological & $\begin{array}{l}\text { Technological obstacles related to research, } \\
\text { development and demonstration }\end{array}$ \\
\hline $\begin{array}{l}\text { Information, education } \\
\text { and training }\end{array}$ & $\begin{array}{l}\text { Lack of awareness of the potential and possibilities for } \\
\text { renewables }\end{array}$ \\
\hline
\end{tabular}

Source: EEA (2001: 27).

- Financial: How accessible is funding for investments in renewable energy projects?

- Fiscal: How favourable is the fiscal infrastructure for renewable energy?

- Administration: How favourable are the administrative arrangements for obtaining permission to construct a renewable energy project?

- Technological development: Is there support for the development of strong national capabilities in renewable energy technologies?

- Information, education and training: Is support given to widely disseminate information on the benefits of renewable energy?

The list of questions, and follow-up discussion by the Agency, provide an important 'baseline' for the present analysis. Together with the discussion of 'promotion strategies' (Table 1.4), these perspectives establish a standardized understanding of barriers and challenges to the promotion of RES at the outset of the Directive period. Two aspects of the above list are, therefore, worth noting at the outset.

First, at face value the list indicates several types of both barriers and potential promotional instruments that are not directly covered by the 
techno-market approach. While 'technological', 'economic' and 'fiscal' factors clearly constitute the essence of the approach, 'legislative' and 'administrative' aspects are at best indirectly included; and 'political' and 'informational-educational' aspects are rarely covered by the techo-market rationale. Granted that the approach often addresses 'market learning', and that it clearly presupposes political and legislative support for technical development and market incentives to 'work' as intended, still the factors in question are rarely if ever addressed in terms of specific instruments for specific barriers and possibilities. The approach simply assumes that the political-legislative conditions will be adjusted to guarantee the 'workings' of technical innovation and 'rational' market-related behaviour, without going into the prospect of proactive political-legislative activity that might promote change on its own terms. Otherwise both political intervention in the marketplace and legislation/administration as 'detailed regulation' are to be deterred. Educational initiatives and informational campaigns can be encouraged, but only in so far as they promote a better understanding of the consequences of market choices.

Second, the list can serve as a conceptual 'foil' for pointing out that no barrier or remedial instrument functions in a vacuum. The separate logics attaching to each category are ideal constructs that identify how the barriers and instruments 'work' within the logic of the category; they do not tell us how the separate inertias and potential transformations work in the real world. They do not account for the interdependence, interaction and even potential self-contradiction among the category phenomena. Even more important in the present context, however, is the fact that the list does not capture the dynamic essence of 'path dependence/path creation'. While the notion of 'barriers' indicates a general type of inertia across all the categories, it does not capture the structural conditioning inherent in historically invested energy constellations (the DES); nor does it give expression to either the resistance of cultural ethos or the potential of countercultural transcendence.

These two observations on the Agency list reflect the basic persuasion of the SUSTEN approach, and it is hoped serve to underline the necessity of an alternative, supplemental perspective. The question of which promotional instruments are most effective in removing which barriers to RES-E deployment can in this view only be answered within a research dialogue that reflectively assesses the interactions and trade-offs between, on the one hand, relatively narrow but robust cross-national predictors (scientific and market rationality), and, on the other, relatively broad but necessary contextual frames (historical and cultural conditioning). Promotional strategies that disadvantage either the one or the other endanger the achievement of effective change. 


\section{The Techno-market Approach}

Having looked briefly at RES barriers and instruments in general, we turn now to the major promotional instruments that have been applied within the techno-market approach. Numerous research and development projects have been carried out in this area since the adoption of the RESE Directive. ${ }^{11}$ The purpose of the present section is to provide a relatively simple terminology for the major types of instruments that have been analysed in these studies. Although the options for alternative lists and categorizations are numerous, we have chosen two major references to portray overall efforts at the level of the EU-15: (1) the approach applied in the REMAC 2000 overview at the start of the period (OECD/IEA 2003); and (2) the leading promotional schemes as defined and assessed by the combined research effort of the Energy Economics Group (EEG) at the Vienna University of Technology and the Fraunhofer Institute for Systems and Innovation Research (ISI) in Karlsruhe (CEER 2004; EWEA 2005; Huber et al. 2004; Ragwitz et al. 2005a, 2005b).

\section{The REMAC 2000 project}

As indicated above, the REMAC 2000 project constituted an important reference for the European Commission during the preparation of the RES-E Directive. The original position of the Commission, with a particularly strong emphasis on market-related initiatives, is clearly reflected in the final report (OECD/IEA 2003). The report reviews each of the principal technologies of the Directive (wind, biopower, small hydropower, solar photovoltaics, solar-thermal and geothermal), assessing them in terms of 'technology status', 'prospects' and 'issues for further progress'. The assessment according to 'prospects' 'seeks to identify major opportunities in the research and market fields to reduce costs, increase performance and enhance applicability'. It focuses (for each technology) on cost-reduction opportunities ('technology development and potential improvements') and market opportunities ('promising market segments' and 'issues favouring market growth') (ibid.: 30).

In dealing with 'issues for further progress', the report concentrates on 'technical issues that comprise crucial aspects for the further development of the technology in order to increase performance and applicability, and to reduce costs'; and 'non-technical issues that affect market potential, including environmental, financial, legal or social issues'. The report concludes its introductory framework by clearly stating: 'The information provided in this study should help policy makers design appropriate frameworks for these renewable technologies at their various stages of progression from laboratory to widespread market use' (ibid.: 30). 
These perspectives succinctly express what we mean by the 'techno-market approach'. They indicate both a 'linear model' of the relationship between technological research and practical application, and a strong bias towards the rationality and effects of ideal market forces ('getting the prices right'). ${ }^{12}$ The way in which the report also treats its declared interest in 'non-technical issues' only strengthens the profile. This is because, first, the category makes no mention of political, historical, cultural, normative or other 'structural' effects; and, second, the application of the category to the different technologies is both very superficial, and, in nearly every case, focused solely on issues that are integrally related to the logic of the techno-market instruments. The only assessment in our view that mentions a major 'non-technical issue' is that for wind power. Here the problem of growing local opposition to onshore wind parks is mentioned (NIMBY - 'not in my back yard'); but the entire section consists of three sentences on this issue alone (ibid.: 169).

\section{The Vienna-Karlsruhe initiatives on promotional schemes}

The second approach to instruments we wish to highlight is that of the influential series of projects carried out by different consortia under the coordination of the Energy Economics Group of the Technical University Vienna, the Fraunhofer Institute in Karlsruhe (ISI), Germany and the Risø National Laboratory in Roskilde, Denmark. Given the numerous and various references to these projects over the years, we refer here only to selected 'final reports' that we feel capture the essence of the work on promotional schemes (Haas et al. 2001; Huber et al. 2004; Ragwitz et al. 2005a and 2005b; Resch et al. 2007; Risø and EWEA 2005). ${ }^{13}$

The framework depicted in Table 1.4 expresses the basic categories of the approach. It has been slightly modified over the years, but not in any significant way. It is also a basic reference point for several other overviews, including an extensive survey of renewable 'support schemes' by the Council of European Energy Regulators (CEER 2004). What we first wish to point out here is that the framework, and the logic of the general approach supporting it, is strongly focused on the rationality and potential impact of the 'schemes'. The work on elaborating these aspects, and on the modelling and simulation of different possible RES-E outcomes for both the individual instruments and different 'packages' of instruments, is the chief thrust of the approach. The achievements of the approach along these lines are 'cutting edge' and of significant importance for academics and policymakers alike. We return to the major results of the project in our concluding assessment, but want here only to profile the instruments themselves.

As defined by the Vienna-Karlsruhe consortium (within the Intelligent Energy Europe Programme), the major promotional schemes/instruments are as follows: 
Table 1.4 Classification of promotion strategies in EU-sponsored research projects

\begin{tabular}{|c|c|c|c|c|}
\hline & & \multicolumn{2}{|c|}{ Direct } & \multirow[t]{2}{*}{ Indirect } \\
\hline & & Price-driven & Quantity-driven & \\
\hline \multirow[t]{2}{*}{ Regulatory } & $\begin{array}{l}\text { Investment- } \\
\text { focused }\end{array}$ & $\begin{array}{l}\text { - Investment } \\
\text { incentives } \\
\text { - Tax incentives }\end{array}$ & - Tendering system & $\begin{array}{l}\text { - Environmental } \\
\text { taxes }\end{array}$ \\
\hline & $\begin{array}{l}\text { Generation- } \\
\text { based }\end{array}$ & $\begin{array}{l}\text { - Feed-in tariffs } \\
\text { - Rate-based } \\
\text { incentives }\end{array}$ & $\begin{array}{c}\text { - Tendering system } \\
\text { - Quota obligation } \\
\text { based on TGCs }\end{array}$ & \\
\hline \multirow[t]{2}{*}{ Voluntary } & $\begin{array}{l}\text { Investment- } \\
\text { focused }\end{array}$ & $\begin{array}{l}\text { - Shareholder } \\
\text { programmes } \\
\text { - Contribution } \\
\text { programmes }\end{array}$ & & $\begin{array}{l}\text { - Voluntary } \\
\text { agreements }\end{array}$ \\
\hline & $\begin{array}{l}\text { Generation- } \\
\text { based }\end{array}$ & - Green tariffs & & \\
\hline
\end{tabular}

Source: Resch et al. (2007) on the basis of Haas et al. (2001).

- Feed-in tariffs (FITs) are generation-based, price-driven incentives. The price per unit of electricity that a utility or supplier or grid operator is legally obliged to pay for electricity from RES-E producers is determined by the system. Thus a federal (or provincial) government regulates the tariff rate. It usually takes the form of either a fixed amount of money paid for RES-E production, or an additional premium on top of the electricity market price paid to RES-E producers. Besides the level of the tariff, its guaranteed duration represents an important parameter for an appraisal of the actual financial incentive. FITs allow technology-specific promotion as well as an acknowledgement of future cost reductions by applying dynamic decreasing tariffs.

- Quota obligations based on tradable green certificates (TGCs) are generation-based, quantity-driven instruments. The government defines targets for RES-E deployment and obliges a particular party of the electricity supply chain (for example, a generator, wholesaler or consumer) to fulfil those targets. Once defined, a parallel market for renewable energy certificates is established and their price is set following demand and supply conditions (forced by the obligation). Hence, for RES-E producers, financial support may arise from selling certificates in addition to the revenues from selling electricity on the power market. With respect to technology-specific promotion in 
TGC systems, this is also possible in principle. Yet it should be noted that a market separation for different technologies will lead to much smaller and less liquid markets.

- Tendering systems are quantity-driven mechanisms. The financial support can either be investment-focused or generation-based. In the first case, a fixed amount of capacity to be installed is announced and contracts are awarded following a predefined bidding process which offers winners a set of favourable investment conditions, including investment grants per installed $\mathrm{kW}$. The generation-based tendering systems work in a similar way. However, instead of providing upfront support, they offer support in the form of a 'bid price' per $\mathrm{kWh}$ for a guaranteed duration.

- Investment incentives establish an incentive for the development of RES-E projects as a percentage of total costs, or as a predefined amount in euros per installed $\mathrm{kW}$. The level of these incentives is usually technology-specific.

- Tax incentives are generation-based, price-driven mechanisms that work through payment exemptions from the electricity taxes applied to all producers. Hence this type of instrument differs from premium feed-in tariffs solely in terms of the cash flow for RES-E producers: it represents a negative cost instead of additional revenue (Resch et al. 2007: 5-6).

These schemes are identified here as the major instruments of the 'techno-market approach'. ${ }^{14}$ In one of the other 'final reports' from the consortium (Ragwitz et al. 2005b: 6), the research team point out that 'more and more voluntary approaches have appeared with on-going market liberalization'. These schemes, which are 'mainly based on the willingness of consumers to pay premium rates for renewable energy', are, however, judged to have had 'negligible impact' on total RES-E deployment, and have apparently not been pursued further within the project. A major conclusion of the consortium's OPTRES project (Assessment and optimization of renewable support schemes in the European electricity market) is that the debate over promotion schemes has been focused on the comparison of the feed-in tariff system, on the one hand; with a system of quota regulation combined with a tradable green certificate market, on the other. These are portrayed as 'opposed systems'. The other policy instruments tender schemes, production tax incentives and investment incentives - are in general not used as principal schemes, but can be applied to supplement one or the other of the most-preferred instruments. Finland is apparently the only EU-15 country to rely mainly on production-tax and investment incentives (Ragwitz et al. 2005b: 6; see also CEER 2004: 27). 


\section{Results thus Far on Promoting RES-E for the EU-15 as a Whole}

As a general reference for the case studies and analysis to follow, we can briefly look at the overall results for phasing in RES-E for the original 15 EU Member States. ${ }^{15}$ The purpose here is simply to put the different RES-E technologies into perspective with respect to: (1) the relative share of each technology within the general scope of the Directive; (2) changes in the shares over the ten-year period encompassing the formulation and transposition of the Directive; and (3) the relative size and rate of change of RES-E vis-à-vis the gross production of electricity. All three dimensions are documented in Table 1.5.

As for the identification of the relevant RES, the categories shown in Table 1.5 are based on the general categories provided by Article 2 (a) of the RES-E Directive (see above). Given that the EU Commission does not provide specific figures for the sources in their official assessment from 2004 (see below), we have had to rely on the figures for the EU-15 provided by OECD/IEA (2006). The definitions of the sources are, however, very similar, so there should be no major discrepancies between the raw data provided by OECD/IEA and those employed (but not published) by the Commission.

What we see from the table is that the most dominant source of RES-E at the outset of the period is clearly large-scale hydropower. This traditional, 'old RES' accounts for almost 91 per cent of all RES-E in the EU15 in 1995. The remaining 9 per cent encompasses wind, biomass, geothermal, photovoltaics and tide-wave-ocean. Of these, the different forms of biomass (solid, gas, municipal waste and liquid), account for a full 6.1 per cent, with the remaining categories all well under 2 per cent.

Looking at the changes between 1995 and 2005 (with roughly the last four years of the period under the direct influence of the Directive), we see that the share of hydropower declines both relatively and absolutely. The decline in actual generation is a reflection of both annual variation in precipitation and a longer-term trend of declining plant efficiency due to 'ageing'. The decline in relative share, however, is primarily a reflection of significant growth in 'new RES' generation (particularly during the period 2000-2005), with only the different types of oceanic power showing no major change. The share of electricity generated from large-scale hydro is reduced to approximately 65 per cent, with wind and biomass emerging as relatively equal front-runners (at roughly 16 per cent apiece) among the new renewables. We already note here, however, that the single largest increase in relative share is for photovoltaics, which, though still very minor in the overall picture, shows a 28 -fold increase.

Finally, it is important to point out that, despite the considerable shifts and relative gains within the RES-E spectrum, the entire gross RES output 
Table 1.5 Gross electricity generation from renewable sources in the EU15, 1995-2005

\begin{tabular}{lrrrc}
\hline Renewable energy source & $\begin{array}{r}1995 \\
\text { GWh }\end{array}$ & $\begin{array}{c}2005 \\
\text { GWh }\end{array}$ & $\begin{array}{c}1995 \\
(\%)\end{array}$ & $\begin{array}{c}2005 \\
(\%)\end{array}$ \\
\hline Wind & 4067 & 68278 & 1.3 & 16.8 \\
Biomass: & 21018 & 65498 & 6.5 & 16.2 \\
$\quad$ solid & $(14770)$ & $(38963)$ & & \\
$\quad$ gas & $(2350)$ & $(15804)$ & & \\
$\quad$ municipal waste & $(3898)$ & $(10264)$ & & \\
liquid & $(0)$ & $(467)$ & & \\
Geothermal & 3478 & 5398 & 1.1 & 1.3 \\
Photovoltaic & 41 & 1169 & 0.01 & 0.28 \\
Tide, wave, ocean & 568 & 534 & 0.19 & 0.12 \\
Hydro* & 291660 & 264746 & 90.9 & 65.3 \\
Total gross RES-E** & 320832 & 405623 & 100 & 100 \\
RES-E as \% of total electricity & 13.9 & 14.4 & & \\
\hline
\end{tabular}

Note:

* Total hydro minus 'pumped storage'.

** From sources listed here (minus industrial waste, non-renewable municipal waste and hydro-pumped storage).

Source: OECD/IEA (2006; 47 and 93).

constitutes only 13.9 per cent of total electricity generation in 1995, and that this share increases to only 14.4 per cent in 2005 . We are, in other words, looking at very small changes in what is still a relatively marginal phenomenon. Suffice it to say that numerous analyses indicate that the potential of energy-conserving initiatives for the electricity sector is much higher than the total share of both 'old' and 'new' renewable sources.

\section{Assessing progress on RES-E within the Member States of the EU-15}

The European Commission is obliged by the RES-E Directive to provide periodic progress reports. Reviews have been presented in 2004 (CEC 2004), 2005 (CEC 2005) and 2007 (CEC 2007). We return to these reports in the concluding chapter, but wish here to provide a general introduction to the case studies by giving a brief overview of the most recent evaluation of RES-E achievements for the individual countries and technologies. Table 1.6 shows the Commission figures for the EU-15 as of 2005, ranked from the most to the least successful in pursuing their indicative targets.

With reference to the results shown in Table 1.6, the following points must be taken into consideration. (1) For reasons of 'most relevant 
comparison' with our case studies, we only present data for the EU-15 Member States plus Norway. (2) The baseline ('reference') dates and dates for 'normalized penetration' are the same for all states presented (1997 and 2005). (3) The figures for 'normalized penetration' have been standardized to take into account seasonal variations in rainfall (for large- and smallscale hydro) and wind conditions. (4) The rankings are apparently based on two key criteria:

- 'Mainly' on the 'percentage degree of achievement of the target'. This is interpreted as follows: 'A country will ideally have reached 40 per cent of the target in 2004 and 50 per cent in 2005.'

- Further: 'new elements in the support framework for 2005 and the first half of 2006 are also considered. In addition to official policies, the perspective of investors is also taken into account as it provides a good basis for assessing the viability of the renewable energy market in a country and the healthiness of the market' (CEC 2007: 5).

Applying these criteria, the report classifies the entire EU-25 into five ranked categories. These are identified as:

1. Perfect: on track for meeting 2010 target (-);

2. Current developments provide good opportunity to reach 2010 target (:)

3. With additional efforts: good chance of reaching the 2010 target $\odot$

4. Strong additional efforts needed to reach the 2010 target $(8$

5. Far from commitment $\otimes: 8$

Given that we shall later want to compare the assessments by the Commission with the information and perspectives of the in-depth case studies, we must comment on the criteria applied in the official report.

More than anything else, perhaps, the criteria indicate the type of decisions and compromises that must be made whenever the Commission takes on the task of assessing the comparative performance of Member States on directives. This is clearly never a question of totally 'objective evaluation', but more a matter of negotiated and relativized 'grading'.

In the present case this is first of all apparent in that the first criterion applied in the report is highly dependent on both the initial baseline for the reference year and the indicated target that was negotiated on this basis. Assuming that the Commission has used the baseline figures from the reference year of 1997, and accepting the fact that they operate with a ten-year time span for achieving the targets, this means that their basis for assessing progress on the 'percentage degree of achievement of the target' is the 


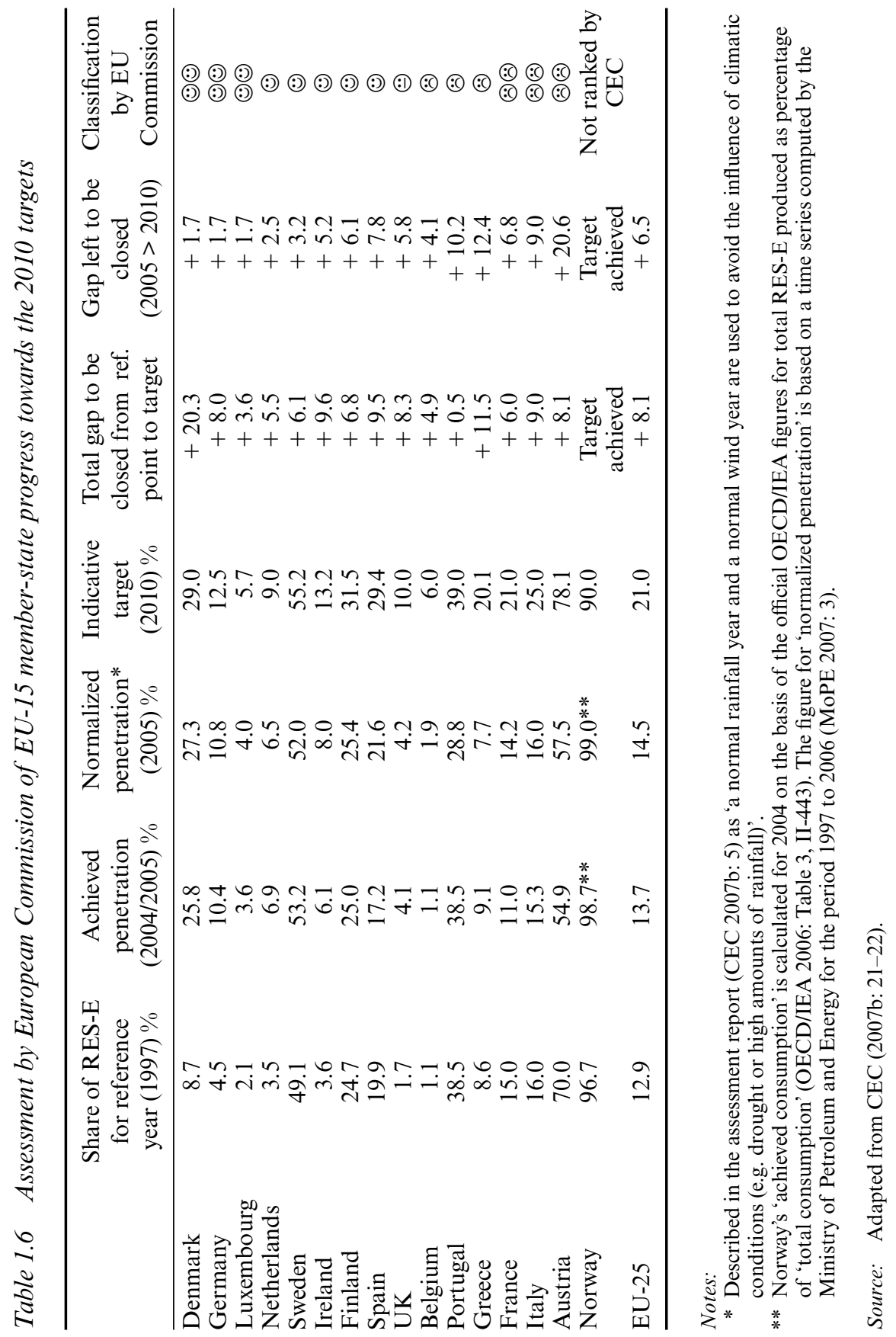


difference between the reference baseline and the target. We have listed these figures separately in Table 1.6, and they show that the number of percentage points to be negotiated by the Member States varies considerably: from a spread of 0.5 points for Portugal to 20.3 points for Denmark. This means that the annual improvement necessary to reach the 2010 target varies significantly from country to country, and that the only apparent reason for this is the level negotiated for the reference year.

As it is further clear that the differences in baselines are not simply a reflection of the level of large-scale hydro (since the country showing the largest 'gap' between baseline and target, Denmark, had virtually no largescale hydro at the start of the period), we must assume that the differences between baselines and targets are conditioned by other contextual factors. In the case of Denmark this must reflect the strong progress that the country had already made in 1997 on the promotion of wind power for electricity. But this contextual factor is neither intuitive nor systematically applied across the EU-15 (the difference between Germany with a 'gap' of 8.0 percentage points and Spain with a gap of 9.5 points illustrates this), so there must be other considerations that explain the differing magnitudes of the RES-E challenge.

Presumably these considerations lie in the second criterion: namely, that some sort of general policy assessment, related to the RES-E specifics of each Member State, underlies the determination of both the reference point and the indicative target. It is apparently this type of policy assessment that is expressed in the second criterion listed above, but which, to our knowledge, has neither been systematically communicated by the Commission nor analysed by independent researchers. Given the considerable latitude of opinion that exists as to what is or isn't an 'effective promotional scheme', and given, further, the very different and conflictual interests that can influence member-state positions on the nature and profile of a national RES-E policy, we must, as a matter of course, assume that both the targets themselves and the business of reporting on them are strongly dependent on contextual factors.

This is, therefore, yet another reason why independent in-depth case studies of RES-E deployment can provide important information for the overall assessment of both progress thus far and the way forward. As outlined above, the national teams of the SUSTEN project have been given very general guidelines as to the types of information necessary for an assessment of the effects of path dependence and the potential of path creation. The main thrust of the case studies is, however, descriptive: an attempt to grasp the national 'storyline' in a way that brings forth a richer and more nuanced understanding of what may, or may not, lie behind the five-year evaluation of the European Commission. 
Table 1.7 The case studies of the SUSTEN project listed according to degree of fossil-fuel dominance in the generation of electricity (1999, \% shares)

\begin{tabular}{lcrrrrrc}
\hline & Coal & $\begin{array}{c}\text { Oil } \\
\text { Netherlands }\end{array}$ & $\begin{array}{c}\text { Natural } \\
\text { gas }\end{array}$ & Nuclear & Hydro & Other $\begin{array}{c}\text { Total share } \\
\text { of fossil-fuel } \\
\text { generation }\end{array}$ \\
\hline Denmark & 52 & 13 & 24 & 0 & 0 & 12 & 89 \\
Ireland & 27 & 28 & 32 & 0 & 4 & 9 & 87 \\
Spain & 37 & 12 & 9 & 29 & 11 & 3 & 58 \\
Finland & 14 & 1 & 14 & 33 & 18 & 20 & 29 \\
Austria & 9 & 5 & 15 & 0 & 68 & 3 & 29 \\
Sweden & 2 & 2 & 0 & 47 & 46 & 2 & 4 \\
Norway & $<0.5$ & 0 & 0 & 0 & 99 & $<0.5$ & $<0.5$ \\
\hline
\end{tabular}

Sources: Table 1.1 above (from Rowlands 2005); IEA (2001).

\section{Realizing the RES-E Directive: a common goal for eight uncommon cases}

In presenting the results from the eight national case studies, we decided to list them in an order that clearly reflects the enormous differences among the countries with respect to the 'dominant energy system'. As explained in the preface to the present volume, we could have chosen other countries as cases, or we could have expanded the number of cases. For the reasons outlined, we have done neither. We feel very strongly, however, that this is not an issue of key importance for the study and its results. The major purpose of the study is to document and assess the contextual factors that 'ground' and 'condition' the technical and market factors influencing the promotion of RES-E. What this requires is an 'interesting' sample of European states: a sample that allows for robust generalizations on the research question within the budgetary and administrative restraints of the project. We know that the sample chosen accommodates the latter, and we believe that it promises the former. We hope to hear from both research colleagues and policy practitioners as to the wisdom and relevance of the approach.

So as to illustrate the degree of variation across the eight case studies, we present them in an order that reflects the radically different nature of the energy systems within which the RES-E Directive is to be realized as goal-directed 'change'. Table 1.7 lists the eight cases according to their degree of fossil-fuel dependence at the outset of the period of implementation (1999). We see here that the systems vary from near-total fossil-fuel dominance of electricity generation in the Netherlands (91 per cent), to 
virtually zero impact for Norway (the miniscule generation from coal is on the Arctic island of Svalbard). In between we find countries at numerous different levels, and with highly different compositions, of fossil-fuel dominance. We also see that the roles of hydropower and nuclear energy differ considerably across the eight cases. While Norway usually generates nearly 100 per cent of all electricity from hydropower, and Austria generates 68 per cent, the Netherlands and Denmark have virtually no indigenous hydro generation. Differing dependences on nuclear power are also distinctive, with Sweden, Finland and Spain all showing significant shares of generation, while the source is totally absent in Denmark, Ireland, Austria and Norway.

Clearly, with such markedly different constellations of indigenous energy systems, it would be strange indeed if the various manifestations of these 'paths' did not make the promotion of RES-E by a standardized model highly 'dependent'. The overriding purpose of the current study is to document the effect of these dependences on the implementation of the RES-E Directive, so as to draw lessons for more effective 'path creation' within and across the European Economic Area.

\section{NOTES}

1. See the annex to the RES-E Directive as amended by the Treaty of Accession for the EU10 (OJEC 2004).

2. These included the following (with the addresses of their original websites): ManagEnergy: http://www.managenergy.net/; Renewable Energy Partnerships: http:// europa.eu.int/comm/energy/res/renewable_energy_partnerships/index_en.htm; EnerIURE: http://www.jrc.es/cfapp/eneriure/welcome.html; PRETIR: http://www. greenprices.com/eu/doc/pretireureport.pdf; REMAC 2000: http://www.renewable-energypolicy.info/remac/; MITRE: http://mitre.energyprojects.net/; REACT: http:// www. react.novem.org/; ElGreen and Green-X : http://www.green-X.at; ADMIRE-REBUS: http://www.admire-rebus.net/. Links to most of these projects are available at the Intelligent Energy Europe website: http://ec.europa.eu/energy/intelligent/index_en. $\mathrm{html}$. We return to the general perspectives and implications of these projects for policy assessment in the concluding chapter.

3. The choice of the joint concepts was inspired by an earlier work by the Danish member of the SUSTEN team, Peter Karnøe, who, with his colleague, Raghu Garud, had published a collection of path-breaking studies on innovation and change entitled 'Path dependence and creation' (Garud and Karnøe 2001). An application of the ideas by the same authors to comparative analyses of wind-turbine technology in Denmark and the USA (Garud and Karnøe 2003) was particularly relevant, matching similar ideas that had been employed by other members of the team.

4. The analogy of 'medium' and 'message' refers to the work of Marshall McLuhan (1964): the 'medium' of communication in many contexts can be so important as to constitute the 'message' of the phenomenon in question. We are not saying here that the 'medium' of the dominant energy system is the sole, or even the most essential, 'message' - but rather that an understanding of how RES-E is communicated and integrated is dependent on an understanding of the 'medium' of national, regional and local conditioning factors. 
5. Use of the term 'inertia' is inherent in the path-dependence concept. As conventionally defined within physics (the Concise Oxford Dictionary), inertia connotes 'a property of matter by which it continues in its existing state of rest or uniform motion in a straight line, unless that state is changed by external force'. The notion of 'embeddedness' adds the connotation that the inertia in question is a manifestation of contextual factors that 'embed' and 'ground' the given 'path', and which - given their constituted symbolic-normative nature - are amenable to redefinition, revaluation and change.

6. Unless otherwise stated, all citations here are from Liebowitz and Margolis (1998: 2-4), as posted at Liebowitz's website. The principal source for the concept in economics is Arthur (1994). See the relevant treatment in Brekke et al. (2005), where special emphasis is placed on the idea of 'market lock-in'. As used in the SUSTEN project, the concept is most directly related to the work of Garud and Karnøe (2001, 2003). In this view, the concept reflects those factors affecting the potential for innovative change that arise from crucial decisions as to how RES can and should be developed. We are interested in both (1) what makes existing energy constellations/systems more or less resistant to the introduction of the renewable-energy technologies designated by the RES-E Directive, and (2) what consequences arise from making specific alternative 'path' choices in the development and application of RES-E.

7. It must be pointed out here that Liebowitz and Margolis are best known for their claim that virtually all of the major empirical references thought to substantiate the economic version of path dependence ('increasing returns to adoption', as systematized by Arthur 1994) - including the QWERTY keyboard case - are what they refer to as 'myths'. In other words, they claim that the empirical basis for the 'increasing returns to adoption' version is weak to non-existent. It must also be stated, however, that they do not thereby discount the idea per se.

8. Note that this condition is dependent on the specific economic approach to path dependence within the discourse. The efficiency question is specifically related to the position of Arthur (1994) and others, and its application by Liebowitz and Margolis as a criterion for differentiating between second- and third-degree path dependence reflects this. From a more general perspective, the efficiency issue can be seen as one of many possible 'regrettable' 'imperfect prediction results'.

9. On the general concept of 'eco-efficiency', see DeSimone and Popoff (2000) and Bleischwitz and Hennicke (2004). On the difference between 'eco-efficiency' and 'ecoeffectiveness' (crucial in the context of RES-E promotion), see Ruud $(2002,2004)$ and Ruud et al. (2007). Whereas 'eco-efficiency' sets standards for single-product chains and life-cycle analysis, 'eco-effectiveness' aims to assess the total systemic (cumulative and interactive) impact of single-product change.

10. The differentiation between 'idiographic' and 'nomothetic' approaches in the social sciences is a well-known aspect of the meta-scientific discussion of comparative methodology. Whereas the former attempts to grasp the particularity and individuality of a particular case ('idios' = own, private), the latter focuses on deriving 'lawlike' generalizations from similarities across the units ('nomos' = law).

11. There are numerous websites with documentation of the leading projects. We recommend the following, all with links to other, more specialized, sites: Programme for Intelligent Energy Europe (IEE) under DG TREN: http://ec.europa.eu/energy/ intelligent/index_en.html; The Energy Research Centre of the Netherlands: http:// www.ecn.nl/en/; The Energy Economics Group at the Vienna University of Technology: http://www.erec-renewables.org/default.htm; and The European Renewable Energy Council (EREC): http://www.erec-renewables.org/default.htm. All sites accessed on 26 July 2007.

12. For alternative views of the 'linear model' of science see Ziman (1984), Stokes (1997) and Nowotny et al. (2001); and for recent (and highly relevant) critiques of market rationality, see Whitley (2002), Nelson (2005), and (in Norwegian) Tranøy (2006).

13. The major projects coordinated by the Vienna-Karlsruhe consortium are: GreenX (http://www.green-x.at/); FORRES 2010 (http://www.eu.fraunhofer.de/forres/); and 
OPTRES (http://www.optres.fhg.de/). We return to the cumulative results of these projects in the concluding chapter.

14. For other similar lists of instruments, see Menanteau et al. (2003), Reiche and Bechberger (2004), Held et al. (2006) and Lund (2007).

15. The time frame and data sources used in this section are chosen to correspond with the categories and perspectives used in the other tables of the chapter, as well as in the official assessment of the EU Commission (CEC 2007) discussed in the following section here. A more general and updated assessment of the status of implementation emerges from the individual case studies, and will be summarized for the EU-15 in the concluding chapter.

\section{REFERENCES}

Arthur, W.B. (1994), Increasing Returns and Path Dependence in the Economy, Ann Arbor, MI: University of Michigan Press.

Bleischwitz, R. and P. Hennicke (eds) (2004), Eco-efficiency, Regulation and Sustainable Business, Cheltenham, UK and Northampton, MA, USA: Edward Elgar.

Brekke, K.A., O. Mosvold Larsen and W.M. Lafferty (2005), Market-based lock-in as a challenge for eco-design strategy: Probing the compatibility between economic and industrial-ecological approaches, Report no. 2/2005, Oslo: ProSus, University of Oslo.

CEC (1997), 'Communication from the Commission: Energy for the future: Renewable sources of energy, White Paper for a community strategy and action plan', $\operatorname{COM(97)} 599$ final, Brussels, 26 November, Commission of the European Communities.

CEC (2004), 'Communication from the Commission to the Council and the European Parliament: The share of renewable energy in the EU Commission Report in accordance with Article 3 of Directive 2001/77/EC, evaluation of the effect of legislative instruments and other Community policies on the development of the contribution of renewable energy sources in the EU and proposals for concrete actions', $\operatorname{COM(2004)} 366$ final, Brussels, 26 May, Commission of the European Communities.

CEC (2005), 'Communication from the Commission: The support of electricity from renewable energy sources', $\operatorname{COM}(2005) 627$ final, Brussels, 7 December, Commission of the European Communities.

CEC (2007), 'Communication from the Commission to the Council and European Parliament: Green Paper follow-up action report on progress in renewable electricity', $\operatorname{COM}(2006) 849$ final, Brussels, 10 January, Commission of the European Communities.

CEER (2004), 'Current experience with renewable support schemes in Europe', CEER Report, September, Brussels: Council of European Energy Regulators.

Cohen, M.A. (1999), 'Monitoring and enforcement of environmental policy', in H. Folmer and T. Tietenberg (eds), International Yearbook of Environmental and Resource Economics, 1999/2000, Cheltenham, UK and Northampton, MA, USA: Edward Elgar, pp. 44-106.

DeSimone, L.D. and F. Popoff (with The World Business Council for Sustainable Development) (2000), Eco-efficiency: The business link to sustainable development, Cambridge, MA: The MIT Press. 
EC (2007), Activities of the European Union: Summaries of legislation, Energy website, EUROPA, European Communities: http://europa.eu/scadplus/leg/en/ s 14000.htm, 29 June.

Eden, S. (1996), 'Public participation in environmental policy: considering scientific, non-scientific and counter-scientific contributions', Public Understanding of Science, 5 (3), 183-204.

EEA (2001), 'Renewable energies: success stories', in Environmental Issue Report, No. 27, Copenhagen: European Environment Agency.

European Environment (2005), 'Economic policy: Barroso defends his focus on employment in new Lisbon strategy', European Environment, 3 January, available at the Goliath-Business Knowledge on Demand website: http://goliath.ecnext. com/coms 2/browse_R_E004-200501, 16 November 2007.

EWEA (2005), Support Schemes for Renewable Energy: A comparative analysis of payment mechanisms in the EU, Brussels: European Wind Energy Association.

Garud, R. and P. Karnøe (eds) (2001), Path Dependence and Creation, Mahwah, NJ and London: Lawrence Erlbaum.

Garud, R. and P. Karnøe (2003), 'Bricolage versus breakthrough: distributed and embedded agency in technology entrepreneurship', Research Policy, 32, 277-300.

Haas, R., T. Faber, L. Green, M. Gual, C. Huber, G. Resch, W. Ruijgrok and J. Twidell (2001), Review Report on Promotion Strategies for Electricity from Renewable Energy Sources in EU Countries, compiled with the cluster 'Green Electricity' cofinanced by the 5th Framework Programme of the European Commission, Vienna: Institute of Energy Economics, Vienna University of Technology.

Hajer, M.A. (1995), The Politics of Environmental Discourse: Ecological modernisation and the policy process, Oxford: Oxford University Press.

Held, A., M. Ragwitz and R. Hans (2006), 'On the success of policy strategies for the promotion of electricity from renewable energy sources in the EU', Energy \& Environment, 17 (6), 849-68.

Héretier, A. (2002), 'New modes of governing in Europe: policy-making without legislating', Vienna: Renner-Institut, available at http://www.renner-institut.at/ download/texte/heritier.pdf.

Huber, C., T. Faber, R. Haas, G. Resch, J. Green, S. Ölz, S. White, H. Cleijne, W. Ruijgrok, P.E. Morthorst, K. Skytte, M. Gual, P. Del Rio, F. Hernández, A. Tacsir, M. Ragwitz, J. Schleich, W. Orasch, M. Bokemann and C. Lins (2004), Final Report of the Project Green- $X$ (within the 5th Framework Programme of the European Commission, DG Research - ENG2-CT-2002-00607), Green-X report, November, available at http://www.green-x.at.

IEA (2001), Energy Policies of IEA Countries, 2001 Review, Paris: International Energy Agency Press.

Lafferty, W.M. (ed.) (2001), Sustainable Communities in Europe, London: Earthscan.

Lafferty, W.M. (ed.) (2004), Governance for Sustainable Development: The challenge of adapting form to function, Cheltenham, UK and Northampton, MA, USA: Edward Elgar.

Lafferty, W.M. and K. Eckerberg (eds) (1998), From the Earth Summit to Local Agenda 21: Working towards sustainable development, London: Earthscan.

Lafferty, W.M. and J. Meadowcroft (eds) (1996), Democracy and the Environment: Problems and prospects, Cheltenham, UK and Lyme, USA: Edward Elgar.

Lafferty, W.M. and J. Meadowcroft (eds) (2000), The Implementation of Sustainable Development in High-Consumption Societies, Oxford: Oxford University Press. 
Lafferty, W.M. and M. Narodoslawsky (eds) (2003), Regional Sustainable Development in Europe: The challenge of multi-level cooperative governance, Oslo and Prague: ProSus.

Lafferty, W.M., J. Knudsen and O.M. Larsen (2007), 'Pursuing sustainable development in Norway: the challenge of living up to Brundtland at home', European Environment, 17, 177-88.

Lauber, V. (2002), 'Renewable energy at the EU level', in D. Reiche (ed.), Handbook of Renewable Energies in the European Union: Case studies of all Member States, Frankfurt am Main: Peter Lang, pp. 25-36.

Lauber, V. (2005), 'Renewable energy at the level of the European Union', in D. Reiche (ed.), Handbook of Renewable Energies in the European Union, Frankfurt am Main: Peter Lang, pp. 19-38.

Liebowitz, S.J. and S.E. Margolis (1995), 'Path dependence, lock-in and history', Journal of Law, Economics, \& Organization, 11 (1), 205-26.

Liebowitz, S.J. and S.E. Margolis (1998 [2004]), 'Path dependence', in The New Palgrave Dictionary of Economics and the Law, London: Macmillan. Version accessed is posted at website of S.J. Liebowitz: http://www.utdallas.edu/ 1 iebowit/palgrave/palpd.html.

Lund, P.D. (2007), 'Effectiveness of policy measures in transforming the energy system', Energy Policy, 35, 627-39.

McLuhan, M. (1964), Understanding Media: The extensions of man, New York: McGraw-Hill.

Menanteau, P., D. Finon and M.-L. Lamy (2003), 'Prices versus quantities: choosing policies for promoting the development of renewable energy', Energy Policy, 31, 799-812.

MoPE (2007), 'Reports in accordance with the Directive 2001/77/EC on the promotion of electricity produced from renewable energy sources in the internal electricity market', Report to the EEA Joint Committee, prepared by the Norwegian Ministry of Petroleum and Energy, available at http://www.regjeringen.no/ Upload/OED/Vedlegg/03-01052-41_Reports_in_accordance_with_the_ Directive_20-_0717-EC_522610.pdf.

Nelson, R. (ed.) (2005), The Limits of Market Organization, New York: Russell Sage Foundation.

Nowotny, H., P. Scott and M. Gibbons (2001), Re-thinking Science: Knowledge and the public in an age of uncertainty, Cambridge: Polity Press.

OECD/IEA (2003), Renewables for Power Generation: Status and prospects, Paris: IEA Publications.

OECD/IEA (2006), Renewables Information, 2006, Paris: IEA Publications.

OJEC (2001), 'Directive 2001/77/EC of the European Parliament and of the Council of 27 September 2001 on the promotion of electricity produced from renewable energy sources in the internal electricity market', Official Journal of the European Communities, L 283/33-40, 27 October.

OJEC (2004), 'Directive 2001/77/EC of the European Parliament and of the Council of 27 September 2001 on the promotion of electricity produced from renewable energy sources in the internal electricity market' (OJ L283, 27.10.2001, p. 33), 200110077 EN-01.05.2004-001.001. (As amended by the Treaty of Accession, Official Journal of the European Communities, L 236, 23.09.2003, p. 33. Available at http://eurlex.europa.eu/LexUriServ/site/en/consleg/2001/L/ 02001L0077-20040501-en.pdf).

OJEU (2003), 'Documents concerning the accession of the Czech Republic, the Republic of Estonia, the Republic of Cyprus, the Republic of Latvia, the 
Republic of Lithuania, the Republic of Hungary, the Republic of Malta, the Republic of Poland, the Republic of Slovenia and the Slovak Republic to the European Union', Official Journal of the European Union, Legislation, L 236, Vol. 46, 23 September. Available at http://eur-lex.europa.eu/JOHtml.do?textfield2= 236\&year $=2003 \&$ Submit $=$ Search\&serie $=$ L.

Ragwitz, M., J. Schleich, C. Huber, G. Resch, T. Faber, M. Voogt, R. Coenraads, H. Cleijne and P. Bodo (2005a), Analysis of the EU Renewable Energy Sources Evolution up to 2020 (FORRES 2020), Final report of the research project FORRES 2020 of the European Commission DG TREN (tender no. TREND/D2/10-2002), Brussels: European Communities.

Ragwitz, M., G. Resch, T. Faber, and C. Huber (2005b), Monitoring and Evaluation of Policy Instruments to Support Renewable Electricity in EU Member States, Summary report from a research project funded by the German Federal Ministry for the Environment, Nature Conservation and Nuclear Safety (funding label 203 41112), Karlsruhe: Fraunhofer Institute for Systems and Innovation Research.

Reiche, D. and M. Bechberger (2004), 'Policy differences in the promotion of renewable energies in the EU member states', Energy Policy, 32, 843-9.

Resch, G., T. Faber, R. Haas, C. Huber, M. Ragwitz, A. Held, P.E. Morthorst, S.G. Jensen, R. Coenraads, M. Voogt, G. Reece, I. Konstantinaviciute and B. Heyder (2007), Recommendations for Implementing Effective and Efficient Renewable Energy Policies, Report from the project on 'Assessment and optimization of renewable energy support schemes in the European electricity market (OPTRES - DG TREN, European Commission - contract no. EIE/04/073/S07.38567), Energy Economics Group (EEG), Institute of Power Systems and Energy Economics, Vienna: Vienna University of Technology.

Risø and EWEA (2005), 'Stable conditions for developing a European-wide framework for expansion of renewable energy technologies', Re-Xpansion, Work Package 2, Evaluation of Renewable Support Schemes, Final Report, Roskilde: Risø National Laboratory.

Rowlands, I.H. (2005), 'The European directive on renewable electricity: conflicts and compromises', Energy Policy, 33, 967-72.

Ruud, A. (2002), 'Industry and environmental responsibility: from proactive to reactive public policies', in W.M. Lafferty, M. Nordskag and H.A. Aakre (eds), Realizing Rio in Norway: Evaluative studies of sustainable development, Oslo: ProSus, University of Oslo, pp. 63-86.

Ruud, A. (2004), 'Partners for progress?: The role of business in transcending business as usual', in W.M. Lafferty (ed.), Governance for Sustainable Development, Cheltenham, UK and Northampton, MA, USA: Edward Elgar, pp. 221-45.

Ruud, A., W.M. Lafferty, R. Marstrander and O. Mosvold Larsen (2007), Exploring the Conditions for Adapting Existing Techno-industrial Processes to Ecological Premises: A summary of the CondEcol project, Report 1/2007, Oslo: ProSus, University of Oslo.

Smeets, E. and R. Wetering (1999), Environmental Indicators: Typology and overview, Technical Report No. 25, Copenhagen: European Environment Agency.

Statistics Norway (2007), 'Produksjon, import, eksport og forbruk av elektrisk kraft. 1950, 1955 og 1960-2005. GWh' (Production, import, export and consumption of electric power. 1950, 1955 and 1960-2005. GWh - in Norwegian), available at http://www.ssb.no/emner/10/08/10/elektrisitetaar/tab-2007-05-2412.html. 
Stavins, R.N. (2002), Experience with Market-based Environmental Policy Instruments, The Fondazione Eni Enrico Mattei Nota di Lavoro Series Index, Nota di Lavoro 52:2002, Economic Theory and Applications, available at http://www.feem.it/web/activ/.

Stokes, D.E. (1997), Pasteur's Quadrant: Basic science and technological innovation, Washngton, DC: Brookings Institution Press.

Tranøy, B.S. (2006), Markedets Makt Over Sinnene (The Power of the Market over Minds - in Norwegian), Oslo: Aschehoug.

Whitley, R. (ed.) (2002), Competing Capitalisms: Institutions and economies, Cheltenham and Northampton, MA, USA: Edward Elgar.

Ziman, J. (1984), An Introduction to Science Studies: The philosophical and social aspects of science and technology, Cambridge: Cambridge University Press. 